OPEN ACCESS

Edited by:

Luis Rodrigo,

Central University Hospital of

Asturias, Spain

Reviewed by:

Atsushi Nakajima,

Yokohama City University, Japan

Ludovico Abenavoli,

University of Catanzaro, Italy

*Correspondence:

Ursula Schwab

ursula.schwab@uef.fi

tThese authors have contributed equally to this work and share the first

authorship

Specialty section

This article was submitted to Nutrition and Microbes,

a section of the journal

Frontiers in Nutrition

Received: 29 May 2021

Accepted: 22 June 2021

Published: 22 July 2021

Citation:

Houttu V, Csader S, Nieuwdorp M, Holleboom AG and Schwab U (2021) Dietary Interventions in Patients With Non-alcoholic Fatty Liver Disease: A

Systematic Review and

Meta-Analysis. Front. Nutr. 8:716783.

doi: 10.3389/fnut.2021.716783

\section{Dietary Interventions in Patients With Non-alcoholic Fatty Liver Disease: A Systematic Review and Meta-Analysis}

\author{
Veera Houttu ${ }^{1,2 t}$, Susanne Csader ${ }^{3 t}$, Max Nieuwdorp ${ }^{1,2}$, Adriaan G. Holleboom ${ }^{1,2}$ and \\ Ursula Schwab ${ }^{3,4 *}$
}

${ }^{1}$ Department of Vascular Medicine, Amsterdam University Medical Center, Location Amsterdam Medical Center at the University of Amsterdam, Amsterdam, Netherlands, ${ }^{2}$ Department of Experimental Vascular Medicine, Amsterdam University Medical Center, Location Amsterdam Medical Center at the University of Amsterdam, Amsterdam, Netherlands, ${ }^{3}$ School of Medicine, Institute of Public Health and Clinical Nutrition, The University of Eastern Finland, Kuopio, Finland, ${ }^{4}$ Department of Medicine, Endocrinology and Clinical Nutrition, Kuopio University Hospital, Kuopio, Finland

Background: With no approved pharmacotherapy to date, the present therapeutic cornerstone for non-alcoholic fatty liver diseases (NAFLD) is a lifestyle intervention. Guidelines endorse weight loss through dietary modifications, physical exercise, or both. However, no consensus exists on the optimal dietary treatment.

Objectives: The aim of our systematic review and meta-analysis was to summarize and assess the evidence for applied types of dietary interventions on the liver and metabolic outcomes in patients with NAFLD, aside from any effects of exercise intervention.

Methods: This systematic review was conducted according to the Preferred Reporting Items of Systematic Reviews and Meta-analysis (PRISMA) statement guidelines. The search was conducted in PubMed, Scopus, and Cochrane databases in February 2020. Included were only dietary interventions without exercise. This study was registered at PROSPERO: CRD42020203573.

Results: Eight randomized controlled trials, seven with endpoint reduction of hepatic steatosis, one with an assessment of endpoint fibrosis, were included in this systematic review, five of which were included in the meta-analysis. Mediterranean dietary interventions without energy restriction $(n=3)$ showed significant reduction of intrahepatic lipid content (IHL) (SDM: $-0.57,95 \% \mathrm{Cl}:-1.04,-0.10)$, but there was no significant change in alanine transaminase (ALT) (SDM: 0.59, 95\% Cl: $-0.5,-1.68)$. Hypocaloric dietary interventions with foods high in unsaturated fatty acids $(n=2)$ led to a significant decrease in ALT (SDM: $-1.09,95 \% \mathrm{Cl}:-1.49$, -0.69 ) and aspartate aminotransferase (AST) (SDM: $-0.75,95 \% \mathrm{Cl}:-1.27,0.23$ ); yet effects on steatosis could not be aggregated due to different assessment techniques. Mediterranean diet did not lead to significant changes in concentrations of gamma-glutamyl transpeptidase $(\gamma \mathrm{GT})$, total cholesterol (TC), low-density lipoprotein cholesterol (LDL-C), high-density lipoprotein cholesterol (HDL-C), triglyceride (TG), fasting glucose or insulin, or homeostatic assessment for insulin resistance. 
Conclusions: In patients with NAFLD, Mediterranean and hypocaloric dietary interventions favoring unsaturated fatty acids result in improvements in $\| \mathrm{HL}$ and transaminases. Since many dietary intervention studies are combined with exercise interventions and there is a paucity of ample-sized studies examining dietary interventions on the more advanced and clinically relevant stages of NAFLD, that is active and fibrotic $\mathrm{NASH}$, with multiparametric imaging and liver histology as outcome measures, the optimal dietary invention in NAFLD remains to be defined.

Keywords: non-alcoholic fatty liver disease, diet intervention, liver fat, liver transaminases, lipid metabolism, glucose metabolism, systematic review, meta-analysis

\section{INTRODUCTION}

Non-alcoholic fatty liver disease (NAFLD) has become the most common cause of chronic liver disease worldwide (1-3). Currently, $25 \%$ of the global and $90 \%$ of the obese population have some degrees of NAFLD. The global prevalence of its active stage, non-alcoholic steatohepatitis (NASH), is $\sim 3-5 \%$ (2). NAFLD comprises a spectrum of liver disease, clinically defined as more than $5 \%$ hepatic fat accumulation excluding significant alcohol consumption and other hepatic diseases $(4,5)$. It ranges from benign steatosis to NASH, characterized by hepatocellular inflammation and ballooning, which can subsequently result in hepatic fibrosis $(6,7)$. Fibrotic NASH can progress to cirrhosis and it can lead to hepatocellular carcinoma (HCC), even at the precirrhotic stage. Indeed, several studies have found a strong relation of NAFLD fibrosis stage with liver-related morbidity and mortality and also with all-cause mortality $(8,9)$. Several driving factors for a progressive NAFLD course have been recognized. In addition to obesity, insulin resistance and the related metabolic syndrome (MetS), and Type 2 diabetes mellitus (T2DM) are strongly related to NAFLD. Approximately $60 \%$ of patients with T2DM have NAFLD (10-12). Consequently, patients with T2DM have a 2.5 -fold higher risk of mortality due to chronic liver disease than non-diabetics (13), and this risk is elevated in MetS as well (14). NAFLD often gives mixed hyperlipidemia with elevated concentrations of low-density lipoprotein cholesterol (LDL-C), decreased levels of high-density lipoprotein cholesterol (HDL-C), and triglycerides (TGs); over 50\% of patients with dyslipidemia have NAFLD $(10,15)$. In addition to obesity and T2DM, high-calorie intake, a Western-type diet, a sedentary lifestyle, sleep apneas, and low-grade inflammation arising from gut microbial dysbiosis or inflammatory conditions, such as psoriasis contribute to drive progression along the NAFLD spectrum (16-20).

Cornerstone interventions in halting or reversing NAFLD progression are lifestyle changes toward healthy diet and increased physical activity (21-24). Several international guidelines for the clinical management of NAFLD endorse weight loss either through the combination of dietary modifications and physical activity or either through one of these two alone. A reduction of hepatic steatosis can already be achieved with a weight loss of 5-7\%, and to improve fibrosis and inflammation, more than $10 \%$ of weight loss is suggested $(25,26)$. Several dietary factors, such as increased intake of refined carbohydrates, in particular, fructose and sucrose and foods high in saturated fat, such as processed meat or high fat dairy have been associated with the development of NAFLD (27-29). On the contrary, dietary fiber and unsaturated fatty acids have been shown to reduce de novo lipogenesis, improve insulin sensitivity, increase satiety, and modulate gut microbiota attenuating the development or the onset of NAFLD $(29,30)$. However, there is still no consensus of the macronutrient composition for the dietary modifications for patients with NAFLD. Whereas, the European Association for the Study of the Liver (EASL), European Society for Clinical Nutrition and Metabolism (ESPEN), and American Gastroenterology Association (AGA) propose the Mediterranean style diet, the American Association for the Study of Liver Disease (AASLD) does not directly recommend a particular diet, although the Mediterranean diet is mentioned (21-24). Moreover, recently published systematic reviews (SRs) on dietary modifications include studies with dietary interventions combined with physical activity $(31,32)$. Therefore, the evidence on the effects of specific dietary approaches alone on NAFLD seems poorly aggregated. Of note, none of the SRs studied the effect of dietary modifications on the liver inflammation or fibrosis, the progressive stages of NAFLD related to morbidity and mortality.

In this systematic review, we aimed to review randomized controlled trials (RCTs) with dietary interventions without any exercise or physical activity intervention in patients with NAFLD in order to establish the effect of different dietary modifications on intrahepatic lipid content (IHL), liver fibrosis, and liver function in patients with NAFLD. Additionally, the effects of dietary interventions on body weight, glucose metabolism, and plasma lipid profile were reviewed. This work is of great value due to the inclusion of dietary intervention studies per se, that is, without exercise or physical activity interventions, in well-characterized study populations.

\section{METHODS}

The present SR was performed based on the Preferred Reporting Items of Systematic Reviews and Meta-analysis (PRISMA) statement guidelines $(33,34)$. Patient, intervention, comparison, 
and outcome (PICO) statement was applied in the process. The protocol of this systematic review was registered in PROSPERO database (CRD42020203573).

\section{Search Strategy and Data Sources}

For gathering all RCTs investigating the effect of dietary interventions without exercise intervention on patients with NAFLD, a systematic literature search was performed by an information specialist together with the authors. The search in Pubmed, Scopus, and Cochrane database for clinical trials were conducted until February 2020 by using the keywords, such as "non-alcoholic fatty liver," "NAFLD," "NASH," "steatohepatitis," "diet," "nutrition," "liver enzymes," "liver fat," "blood lipids," and "glucose metabolism."

\section{Eligibility Criteria: Inclusion and Exclusion}

Studies were included when they met the following conditions: (1) RCTs written in English, (2) isocaloric or hypocaloric dietary interventions without exercise intervention and changes in alcohol consumption, (3) a minimum intervention period of 4 weeks, (4) studies conducted on adults (age $\geq 18$ years), (5) diagnosis of NAFLD made either based on histology, ultrasonography (US) including vibration-controlled transient elastography (VCTE) (FibroScan ${ }^{\circledR}$, Echosens, Paris, France.), MRI, or computed tomography (CT), (6) presence of a control group with unchanged or control dietary intervention. Excluded studies were (1) non-human, studies with adolescents, pilot, prospective cohort, and cross-sectional and uncontrolled studies; (2) abstracts, reviews, and case reports; (3) hypercaloric dietary interventions, studies with specific food items, or dietary regimens.

\section{Screening Process}

Two reviewers (SC and $\mathrm{VH}$ ) screened the articles independently based on title and abstract using the Rayyan QCRI program (35). Duplicates were removed. All studies which did not fit into our inclusion and/or exclusion criteria were excluded. After screening for eligibility, full-text articles were resorted independently by the same authors. If agreement could not be reached, US was consulted.

\section{Quality Assessment}

Quality assessment was performed for all eligible studies independently by SC and $\mathrm{VH}$ using the quality assessment tool for clinical trials (36). The tool has a three-category grading system of the Agency for Healthcare Research and Quality (AHRQ) and it is specifically designed to dietary intervention studies. It includes detailed sub-questions under the following main scoring items: (1) general question and study design, (2) participants and compliance, (3) dietary intervention and assessment, (4) outcome, results, and analysis and (5) summary of the study quality. Evaluated studies obtained A-, B-, or Clevels based on the answers, "yes," "no," "cannot tell," or "not applicable" to the sub-questions. Studies rated Level A had the least bias and results were considered valid whereas Level B studies were susceptible to some concern, but not sufficient to invalidate the results. C-level rating indicated significant bias that may invalidate the results in studies.

\section{Data Extraction}

After the screening process and quality assessment, data were extracted from eligible studies independently by the two reviewers ( $\mathrm{SC}$ and $\mathrm{VH}$ ). Extracted data included the outcome variables for the following factors: (1) intrahepatic fat content (IHL) and (2) fibrosis and liver function including (3) alanine aminotransferase (ALT) and (4) aspartate aminotransferase (AST), (5) gamma-glutamyl transferase $(\gamma \mathrm{GT})$, glucose metabolism markers including (10) fasting glucose, (11) fasting insulin, (12) homeostatic model assessment for insulin resistance (HOMA-IR), and plasma lipid profile parameters including (6) total cholesterol (TC), (7) LDL-C, (8) HDL-C, and (9) TG.

\section{Statistical Analysis}

For meta-analyses, R programming software (Version 4.0.3) was used. Changes in mean and standard deviation (SD) before and after the intervention were calculated for each parameter according to the Cochrane Handbook for Systematic Reviews of Interventions (37). Publication-bias detection analyses could not be performed due to lack of power. Meta-analysis was performed for the following outcomes: IHL, ALT, AST, $\gamma \mathrm{GT}$, fasting glucose, fasting insulin, HOMA-IR, TC, LDL-C, HDL-C, and TG. All continuous parameters were displayed as standardized mean difference (SMD) to measure the effect size and were presented with $95 \%$ confidence interval (CI). Fixed or random effect model was used to pool and calculate the SMD from baseline to followup between intervention and control group. $I^{2}$ was used to assess the heterogeneity across the studies. Low heterogeneity was considered if $I^{2}$ was $<25 \%$ and the fixed effect model was applied for the meta-analysis. In case of moderate (25-50\%) and high heterogeneity (>50\%), the random effect model was used.

\section{RESULTS}

\section{Database Search and Study Selection}

Primary search yielded 1,974 records. After the removal of the duplicates, 1,355 were screened based on the abstract and title, and 85 studies were retained for full-text assessment. According to the inclusion and exclusion criteria, eight studies fulfilled the criteria for further analyses including qualitative synthesis. Five of these studies were included in the meta-analysis. All stages of the study selection process are presented in the flow chart (Figure 1).

\section{Quality Assessment}

The quality assessment results are presented in Table 1. Three studies have low risk of bias and the results are considered valid $(42,44,45)$. Some concerns appeared in four studies, mostly because of missing reported randomization methods (39-41, 43). In one of the studies, a significant bias was found not only due to concerns in the study design but also due to the dietary assessment (38). 


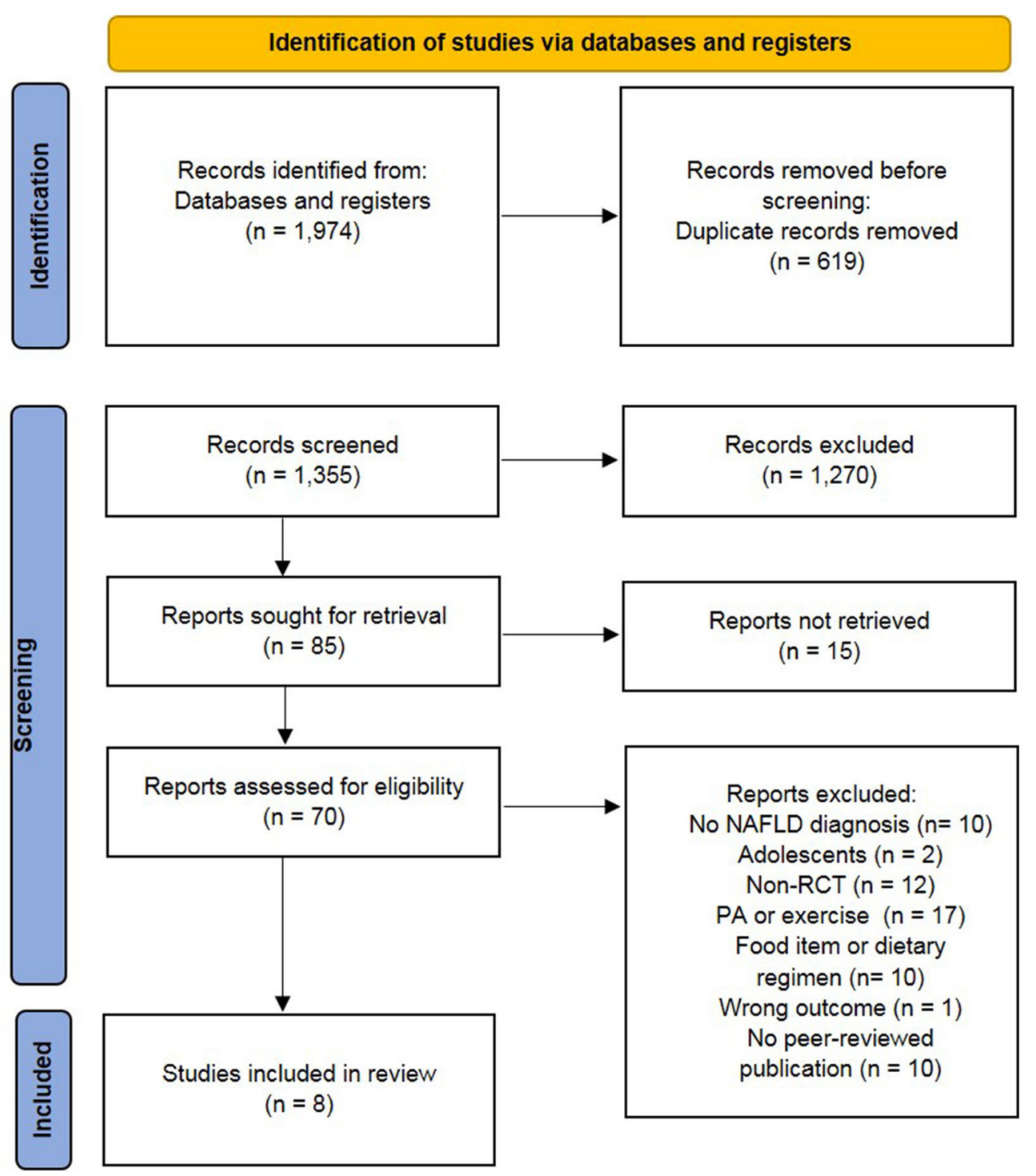

FIGURE 1 | Preferred reporting items of systematic reviews and meta-analysis (PRISMA) flow chart (34). NAFLD, non-alcoholic fatty liver diseases; non-RCT, non-randomized controlled trial; PA, physical activity.

\section{Study Characteristics}

In this systematic review, the sample size of the included studies varied from 12 participants (45) to 112 participants (42). In total, the studies performed interventions with 499 participants with NAFLD. The study duration varied from 6 weeks $(38,45)$ to 24 weeks $(43)$. Three studies had an intervention duration of 12 weeks and two studies were 8week interventions $(39,40)$. In seven studies, the population consisted of both females and males. One study (39) did not report the gender distribution. The mean age ranged from 38 years (38) to 55 years (45). Most of the studies used US or magnetic resonance spectroscopy (MRS) to diagnose and stage NAFLD, and hence classified steatosis only, ranging from steatosis Grade I to Grade III (38-44). Signs of NASH as elevated transaminases, ALT and/or AST, were assessed in six studies $(38-41,44,45)$. One study reported hepatic fibrosis as liver stiffness measurement (LSM) by VCTE (FibroScan ${ }^{\circledR}$ ) (44). One of the studies also had subjects with histologically confirmed NAFLD, where IHL was found to be $11.2 \pm 2.1 \%$ (45). The characteristics of the included studies are presented in Table 1.

\section{Dietary Interventions}

Dietary interventions (Table 2) and the duration of interventions (Table 1) varied between the studies. Four out of eight studies conducted a hypocaloric dietary intervention (38-41), whereas isocaloric diets were followed in four studies (42-45). However, due to high variations in the dietary interventions, only two studies with a hypocaloric dietary intervention $(40,41)$ and three studies with an isocaloric dietary intervention (42-45) 
TABLE 1 | Characteristics and quality assessment results of the included studies.

\begin{tabular}{|c|c|c|c|c|c|c|c|}
\hline $\begin{array}{l}\text { Author, year of } \\
\text { publication and } \\
\text { country }\end{array}$ & $\begin{array}{l}\text { Sample size } \\
\text { (F/M) }\end{array}$ & $\begin{array}{c}\text { Mean age } \\
\text { (years } \pm \text { SD) }\end{array}$ & Disease stage & $\begin{array}{l}\text { Diagnosis } \\
\text { techniques }\end{array}$ & $\begin{array}{c}\text { Outcome } \\
\text { measurement } \\
\text { technique }\end{array}$ & $\begin{array}{c}\text { Duration } \\
\text { (week) }\end{array}$ & $\begin{array}{c}\text { Quality } \\
\text { assessment }^{\mathrm{a}}\end{array}$ \\
\hline $\begin{array}{l}\text { Arefhosseini et al. } \\
\text { (38), Iran }\end{array}$ & $\begin{array}{l}\text { I: } 22(10 / 12) \\
\text { C: } 22(12 / 10)\end{array}$ & $\begin{array}{l}\text { l: } 38.0 \pm 8.1 \\
\text { C: } 40.6 \pm 8.3\end{array}$ & $\begin{array}{l}\text { Steatosis grade } \\
\qquad|-|||\end{array}$ & US & US & 6 & C \\
\hline $\begin{array}{l}\text { Jang et al. (39), } \\
\text { South Korea }\end{array}$ & I: 52 C: 54 & $\begin{array}{l}\text { I: } 43.6 \pm 11.8 \\
\text { C: } 42.4 \pm 3.0\end{array}$ & NA & US & CT & 8 & B \\
\hline $\begin{array}{l}\text { Razavi et al. (40), } \\
\text { Iran }\end{array}$ & $\begin{array}{l}\text { I: } 30(15 / 15) \\
\text { C: } 30(15 / 15)\end{array}$ & $\begin{array}{l}\text { I: } 42.8 \pm 10.6 \\
\text { C: } 39.7 \pm 7.3\end{array}$ & $\begin{array}{l}\text { Steatosis Grade } \\
\qquad|-| I \mid\end{array}$ & US & US & 8 & $\mathrm{~B}$ \\
\hline $\begin{array}{l}\text { Shidfar et al. (41), } \\
\text { Iran }\end{array}$ & $\begin{array}{l}\text { l:25 (8/13) } \\
\text { C:28 (9/13) }\end{array}$ & $\begin{array}{l}\text { l: } 46.1 \pm 8.4 \\
\text { C: } 45.7 \pm 0.8\end{array}$ & $\begin{array}{l}\text { Steatosis mild to } \\
\text { moderate }\end{array}$ & $\begin{array}{c}\text { Increased levels of } \\
\mathrm{AST}^{\star} / \mathrm{ALT}^{\star}\end{array}$ & US & 12 & B \\
\hline $\begin{array}{l}\text { Dorosti et al. (42), } \\
\text { Iran }\end{array}$ & $\begin{array}{l}\text { I: } 47(21 / 26) \\
\text { C: } 47(29 / 18)\end{array}$ & $\begin{array}{l}\text { I: } 43.1 \pm 8.9 \\
\text { C: } 42.4 \pm 8.6\end{array}$ & $\begin{array}{l}\text { Steatosis Grade } \\
\qquad|-|||\end{array}$ & US & US & 12 & $A$ \\
\hline $\begin{array}{l}\text { Misciagna et al. } \\
\text { (43), Italy }\end{array}$ & $\begin{array}{l}\text { I: } 39(13 / 26) \\
\text { C: } 43(10 / 33)\end{array}$ & $\begin{array}{l}\text { I: } 49.3 \pm 10.4 \\
\text { C: } 54.1 \pm 1.4\end{array}$ & $\begin{array}{l}\text { NAFLD moderate } \\
\text { to severe }\end{array}$ & US & US & 24 & $\mathrm{~B}$ \\
\hline $\begin{array}{l}\text { Propezi et al. (44), } \\
\text { Australia }\end{array}$ & $\begin{array}{l}\text { I: } 24(11 / 15) \\
\text { C: } 24(14 / 11)\end{array}$ & $\begin{array}{l}\text { I: } 51.0 \pm 13.4 \\
\text { C: } 53.0 \pm 9.1\end{array}$ & $\begin{array}{l}\text { Steatosis Grade } \\
\qquad|-| I \mid\end{array}$ & MRS-PDFF & $\begin{array}{l}\text { MRS and } \\
\text { Fibroscan }\end{array}$ & 12 & A \\
\hline $\begin{array}{l}\text { Ryan et al. (45), } \\
\text { Australia }\end{array}$ & $12(6 / 6)$ & $55.0 \pm 14.0$ & $11.2 \pm 2.1 \% \mathrm{HL}$ & $\begin{array}{c}\text { Liver histology and } \\
\text { US }\end{array}$ & MRS & 6 & A \\
\hline
\end{tabular}

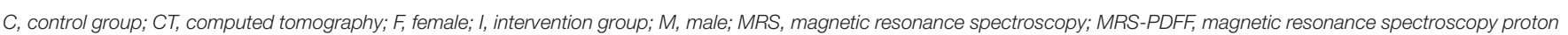

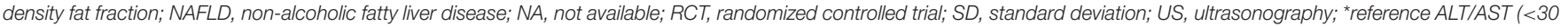
IU/L male, <20 IU/L female). ${ }^{a}$ Quality assessment tool for clinical trials of the Agency for Healthcare Research and Quality (AHRQ).

could be selected for a meta-analysis based on the dietary intervention regimen.

Two studies with hypocaloric dietary intervention were selected for meta-analysis with the focus on the effect of dietary fat intake since both have used foods or dietary pattern high in unsaturated fatty acids compared to their controls. Razavi et al. (40) introduced dietary approaches to stop hypertension (DASH) diet, which is a dietary pattern with restricted intake of salt and salt-containing products, increased consumption of vegetables, fruits, and whole-grain products, as well as dietary fats containing unsaturated fatty acids (46). In the study by Shidfar et al. (41), the intervention diet consisted of a diet with a macronutrient composition toward increased intake of unsaturated fatty acids from olive oil, while the control group had the intake of fat from other unspecified culinary dietary fats. The other two hypocaloric dietary studies by Arefhosseini et al. (38) and Jang et al. (39) could not be integrated in the metaanalysis for comparisons of macronutrient proportions, since the proportions of macronutrients were not comparable between these two.

For the isocaloric studies, three studies were included in the meta-analysis. These studies conducted a Mediterranean dietary intervention with varying macronutrient compositions (43-45), and had as a control group, a low-fat low-carbohydrate diet based on dietary guidelines. In the study by Ryan et al. (45), subjects undertook both diets according to a cross-over design with a washout period of 6 weeks. The Mediterranean diet in these studies mainly consisted of vegetables, fruits, legumes, nuts, and unsaturated dietary fats from vegetable oils. The study by Dorosti et al. (42), which was not included in the meta-analysis, focused on the effect of whole-grain diet compared to the usual cereal and grain products on NAFLD. Characteristics of macronutrient composition, energy content, and food choices of the dietary interventions are described in Table 2.

\section{Meta-Analysis}

For hypo-caloric studies, meta-analyses were conducted for the liver function including ALT and AST (40,41). Analysis could not be performed for IHL, lipid, or glucose parameters in this group due to lack of studies. For the isocaloric group (the Mediterranean diet), meta-analysis could be performed in IHL, ALT, and $\gamma \mathrm{GT}$, as well as for the glucose parameters, such as fasting glucose, fasting insulin, and HOMA-IR, and for the lipid parameters, such as TC, HDL-C, LDL-C, and TG. The ALT was measured only in two studies $(44,45)$, and AST was not analyzed because it was measured in only one study (42). Two studies analyzed TC, LDL-C, and HOMA-IR $(43,44)$, and for $\gamma \mathrm{GT}$, HDL-C, TG, fasting glucose, and insulin, all the three included studies measured these parameters (43-45). Meta-analysis for fibrosis status could not be performed since only one study assessed fibrosis with LSM, a proxy for fibrosis (44). However, paired LSM did not show any significant change after the diet intervention between the intervention and the control group. In another study, the diagnosis of NAFLD by the liver biopsy together with US was an inclusion criterion, but the liver biopsy was not repeated after the intervention as an outcome measure of the intervention (45). Altogether, none of the studies assessed the liver histology or used multiparametric imaging in order to establish the effects of dietary interventions on the active or fibrotic NASH. 
TABLE 2 | Macronutrient composition, content of food items, and energy content of the intervention and control diets of the included studies.

\begin{tabular}{|c|c|c|}
\hline References & $\begin{array}{l}\text { Intervention diet (macronutrient composition, food items, } \\
\text { and energy content } \mathrm{kcal} / \mathrm{d} \text { ) }\end{array}$ & $\begin{array}{l}\text { Control diet (macronutrient composition, food items, and } \\
\text { energy content kcal/d) }\end{array}$ \\
\hline \multicolumn{3}{|c|}{ Hypocaloric dietary interventions } \\
\hline Arefhosseini et al. (38) & $\begin{array}{l}\text { Diet } 1 \\
\text { Carbohydrate: Fat: Protein: 55: 25: } 20 \\
-500 \mathrm{kcal} / \mathrm{d}\end{array}$ & $\begin{array}{l}\text { Diet } 2 \\
\text { Carbohydrate: Fat: Protein: 40: 40: } 20 \\
\text {-500 kcal/d }\end{array}$ \\
\hline Jang et al. (39) & $\begin{array}{l}\text { Low-carbohydrate diet } \\
\text { Carbohydrate: Fat: Protein: 50-60:20-25:20-25 } \\
25 \mathrm{kcal} / \mathrm{kg} \text { of ideal body weight }\end{array}$ & $\begin{array}{l}\text { Low-fat diet } \\
\text { Carbohydrate: Fat: Protein: 60-70:15-20:15-20 } \\
25 \mathrm{kcal} / \mathrm{kg} \text { of ideal body weight }\end{array}$ \\
\hline Razavi et al. (40) & $\begin{array}{l}\text { DASH diet high in fruits, vegetables, whole grains, and low-fat } \\
\text { dairy products and low in saturated fats, cholesterol, refined } \\
\text { grains, sweets, and sodium <2,400 mg/day. } \\
\text { Carbohydrate: Fat: Protein: } 52-55: 30: 16-18 \\
\text {-350-700 kcal based on the computed energy requirement per } \\
\text { subject and BMl. }\end{array}$ & $\begin{array}{l}\text { Control diet with fewer vegetables and fruits, less seeds and legumes, } \\
\text { less low-fat diary, less whole-grains, and more simple sugars. } \\
\text { Carbohydrate: Fat: Protein: 52-55: 30: 16-18 } \\
\text {-350-700 kcal based on the computed energy requirement per } \\
\text { subject and BMl. }\end{array}$ \\
\hline Shidfar et al. (41) & $\begin{array}{l}\text { Carbohydrate: Fat: Protein: 50: } 30: 20 \text {; where } 30 \% \text { of fat from } \\
\text { olive oil and 10\% from other sources (dairy, meats, and nuts). } \\
\text { Target } 5 \% \text { weight reduction based on calculation on age, weight, } \\
\text { and height. }\end{array}$ & $\begin{array}{l}\text { Carbohydrate: Fat: Protein: 50: 30: } 20 \text {; where } 30 \% \text { of the fat was culinary } \\
\text { fat and 10\% from other sources (dairy, meats, and nuts). } \\
\text { Target } 5 \% \text { weight reduction based on calculation on age, weight, and } \\
\text { height. }\end{array}$ \\
\hline \multicolumn{3}{|c|}{ Isocaloric dietary interventions } \\
\hline Dorosti et al. (42) & $\begin{array}{l}\text { Whole-grain diet (List and description of whole-grain foods and } \\
\text { advises to consume at least half of the daily grain servings as } \\
\text { whole grains based on Dietary Guidelines for Americans } 2012 \text {. Two } \\
\text { to three servings of low-fat dairy products, five serving of fruits and } \\
\text { vegetables, and two servings of lean meat, poultry, or fish daily). }\end{array}$ & $\begin{array}{l}\text { Consumption of usual cereals. Two to three servings of low-fat dairy } \\
\text { products, five serving of fruits and vegetables, and two servings of lean } \\
\text { meat, poultry, or fish daily. }\end{array}$ \\
\hline Misciagna et al. (43) & $\begin{array}{l}\text { Low glycemic index Mediterranean diet. } \\
\text { Carbohydrate: Fat: Protein: 50: } 30 \text { ( }<10 \% \text { saturated fat, and } \\
\text { MUFA and PUFA from olive oil, plant and marine sources): } 20\end{array}$ & $\begin{array}{l}\text { Control diet (based on the Italian National Research Institute for Foods } \\
\text { and Nutrition Guidelines) } \\
\text { Carbohydrate: Fat: Protein: 40: 35-40 (<10\% saturated fat): } 20\end{array}$ \\
\hline Propezi et al. (44) & $\begin{array}{l}\text { Mediterranean diet (based on the data on the consumption of } \\
\text { foods in the traditional Cretan diet with alterations to protein intake } \\
\text { to be standardized with the low-fat diet). } \\
\text { Carbohydrate: Fat: Protein: } 40: 35-40 \text { (MUFA and n-3-PUFA): } 20\end{array}$ & $\begin{array}{l}\text { Low-fat diet (based on Australian National Heart Foundation Diet and } \\
\text { the American Heart Association Diet). } \\
\text { Carbohydrate: Fat: Protein: 50: 30: } 20\end{array}$ \\
\hline Ryan et al. (45) & $\begin{array}{l}\text { Mediterranean diet (based on the reported data on the traditional } \\
\text { Cretan diet including meals and meal-based traditional recipes } \\
\text { and food preparation techniques, and foods, such as olives, dried } \\
\text { fruits, nuts, Greek yogurt, fish, and extra virgin olive oil). } \\
\text { Carbohydrate: Fat: Protein: } 40: 40 \text { (MUFA and n-3-PUFA from } \\
\text { plant and marine sources): } 20\end{array}$ & $\begin{array}{l}\text { Low-fat/high-carbohydrate diet (based on the Australian National Heart } \\
\text { Foundation Diet and the American Heart Association Diet). } \\
\text { Carbohydrate: Fat: Protein: 50: } 30 \text { (n-6-PUFAs): } 20\end{array}$ \\
\hline
\end{tabular}

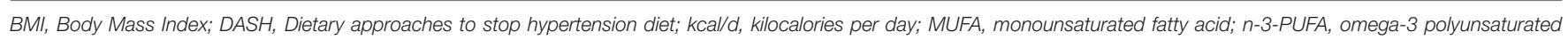
fatty acid; n-6-PUFA, omega-6 polyunsaturated fatty acid.

\section{Liver Parameters}

All studies measured IHL, but different methods were used to assess the liver fat content Table 1. In the hypocaloric group, Arefhosseini et al. (38) reported a significant reduction of hepatic steatosis grade in both groups (intervention: $p=0.011$; control: $p=0.014$ ) and Jang et al. (39) showed significant reduction of the liver fat in the low carbohydrate group (intervention) compared to the low-fat control group (the liver/spleen HU ratio: 0.85 vs. $0.92, p=0.015$ ). Razavi et al. (40) showed significant reduction in the percentage of NAFLD grade within both groups (intervention: $p<0.001$, control: $p<0.001$ ). Shidfar et al. (41) reported a reduction of IHL between the baseline and after the olive oil dietary intervention $(p=0.008)$, but it did not differ from the reduction in the control group. All studies in the isocaloric group reported a decrease in IHL, compared to controls (42-45). Dorosti et al. (42) found a significant decrease in the hepatic steatosis grade in the whole-grain group $(p<$ 0.001)and Propezi et al. (44) reported a significant reduction in IHL in both groups (intervention: $p<0.001$, control: $p<$
$0.001)$, but not between the groups after the intervention. The IHL reduction upon Mediterranean diet $(-5.6 \pm 7.4 \%, p<$ $0.005)$ was significantly higher compared to the low-fat control group $(-1.2 \pm 2.6 \%, p>0.05)$ in the study by Ryan et al. (45). In line with this, between the groups, a significant relative reduction of IHL favoring Mediterranean diet was reported (intervention: $39 \pm 4 \%$ vs. control: $7 \pm 3 \%, p=0.012$ ).

For the meta-analysis, only studies which reported IHL as mean percentage using MRI were considered. These were two studies $(43,44)$ in the isocaloric group with the Mediterranean diet. The IHL was significantly reduced after the Mediterranean diet compared to the control diet (SMD: $-0.57,95 \%$ CI: -1.04 , -0.10 ) (Figure 2). Heterogeneity was not detected among the studies $\left(I^{2}=0 \%, \tau^{2}=0, p=0.58\right)$.

The liver enzymes, ALT and AST, imperfect by clinically widely used proxies for steatohepatitis, were measured in most of the studies, whereas $\gamma \mathrm{GT}$ was measured only in five studies $(39,42,44,45)$. Arefhosseini et al. (38) reported a significant reduction of these liver enzymes in both groups (intervention: 


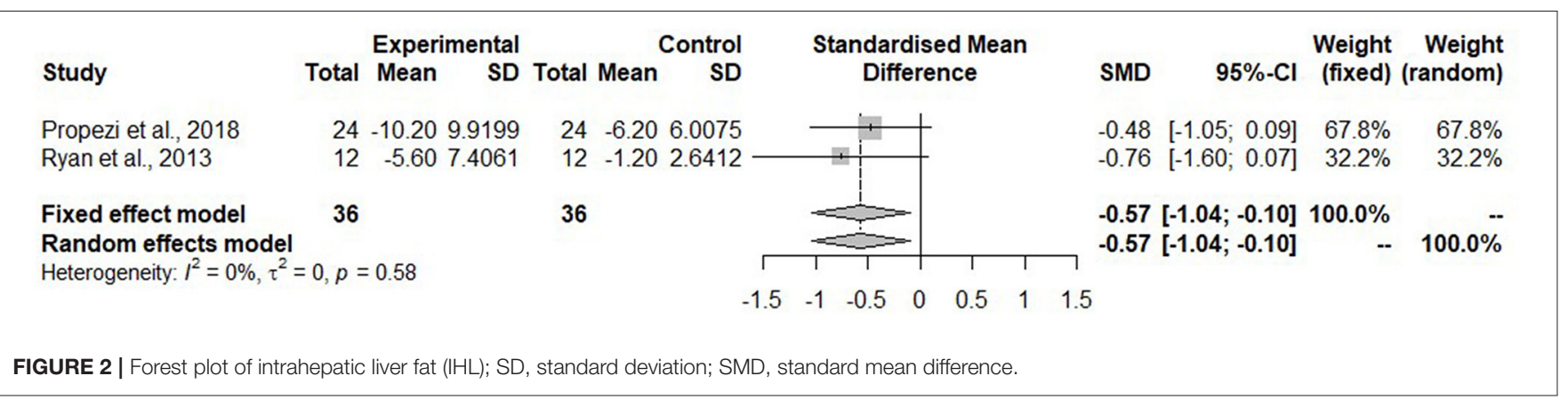

$-9.09 \pm 12.8 \mathrm{IU} / \mathrm{L}, p=0.020$; control: $-8.91 \pm 10.0 \mathrm{IU} / \mathrm{L}$, $p=0.009$ ). Jang et al. (39) (intervention: $-30.47 \pm 26.0 \mathrm{IU} / \mathrm{L}$, $p<0.001$ ) and Razavi et al. (37) (intervention: $-8.4 \pm 12.7$ IU/L, $p=0.02$ ) found a significant reduction of ALT compared to the control group. In addition, Jang et al. (39) reported a significant reduction of AST $(-12 \pm 17.4 \mathrm{IU} / \mathrm{L}, p<0.001)$ in the low carbohydrate intervention and Razavi et al. (40) found the reduction of AST in the DASH diet $(-10.7 \pm 23.1 \mathrm{IU} / \mathrm{L}$, $p=0.01$ ). Shidfar et al. (41) showed a significant reduction of ALT in both groups (intervention: $-12.29 \pm 7.8 \mathrm{IU} / \mathrm{L}, p<0.001$; control: $-4.64 \pm 6.5 \mathrm{IU} / \mathrm{L}, p=0.004)$ as well as AST in the intervention group $(-8.43 \pm 3.4 \mathrm{IU} / \mathrm{L}, p<0.001)$. In the study by Dorosti et al. (42), all liver enzymes significantly decreased in the group with whole-grain foods compared to the control group (ALT: $-22.4 \pm 7.8$ vs. $0.4 \pm 11.17 \mathrm{IU} / \mathrm{L}, p<0.001$; AST: $-5.8 \pm$ 9.1 vs. $1 \pm 6.6 \mathrm{IU} / \mathrm{L}, p<0.001, \gamma \mathrm{GT}:-4.5 \pm 7.2$ vs. $1.7 \pm 12.3$ $\mathrm{IU} / \mathrm{L}, p=0.009$ ). For the Mediterranean diets, Propezi et al. (44) detected significant changes of ALT (intervention: $-8.0 \pm 31.2$ IU/L, $p=0.004$; control: $-12 \pm 40.4 \mathrm{IU} / \mathrm{L}, p=0.049)$ in both groups and $\gamma \mathrm{GT}$ (intervention: $-19 \pm 72.1 \mathrm{IU} / \mathrm{L}, p<0.001$ ) only in the intervention group.

Figure 3A shows the meta-analysis of ALT in the hypocaloric group. The ALT was significantly reduced upon dietary intervention compared to the control group (SMD: $-1.09,95 \%$ CI: $-1.49,-0.69)$ and heterogeneity was not found $\left(I^{2}=0 \%\right.$, $\left.\tau^{2}=0, p=0.85\right)$. For the Mediterranean diet, two studies reported ALT (Figure 3B). The ALT did not change (SMD: 0.07, 95\% CI: $-0.39,0.53)$. The heterogeneity in the effect of the Mediterranean diet was not detected $\left(I^{2}=0 \%, \tau^{2}=0, p=0.83\right)$.

Aspartate aminotransferase was measured in the study with whole-grain dietary intervention by Dorosti et al. (42), but it was not measured in the Mediterranean diet intervention studies. No meta-analysis could be performed. For the hypocaloric interventions, both studies measured AST (Figure 3C). This kind of diet reduced AST significantly compared to the control group (SMD: $-0.75,95 \% \mathrm{CI}:-1.27,0.23$ ). The heterogeneity was moderate, but it was not significant $\left(I^{2}=45 \%, \tau^{2}=0.0632\right.$, $p=0.518)$.

The gamma-glutamyl transferase was not measured in any of the hypocaloric studies, but it was measured in all of the Mediterranean diet interventions. Figure 3D shows that the concentration of $\gamma \mathrm{GT}$ was not changed after the intervention compared to the control group (SMD: 0.04, 95\% CI: $-0.28,0.35$ ) and no heterogeneity was detected $\left(I^{2}=0 \%, \tau^{2}=0, p=0.95\right)$.

\section{Glucose Parameters}

Only Jang et al. (39) and Razavi et al. (40) in the hypocaloric group reported fasting glucose and insulin concentrations. Razavi et al. (40) measured HOMA-IR as well. Only Razavi et al. (40) reported significant changes for insulin $(-3.3 \pm$ $3.2 \mu \mathrm{IU} / \mathrm{mL}, p<0.001)$ and HOMA-IR $(-0.8 \pm 0.9 \mu \mathrm{IU} / \mathrm{ml}$, $p<0.001)$ in the DASH diet. Ryan et al. (45) showed a reduction of glucose concentration for both interventions. In the isocaloric group, Dorosti et al. (42) showed a decrease in insulin $(-2.1 \pm 5.6 \mathrm{mU} / \mathrm{L}, \mathrm{p}<0.05)$ and in HOMA-IR $(-0.5 \pm 0.2, p<0.05)$ in the whole-grain intervention diet. However, after adjusting for baseline values of the outcome, the mean change in food groups and metabolic equivalent of task (MET) value, no significant changes were observed. Misciagna et al. (43) showed a reduction in the glucose and insulin concentration in both intervention groups, but no statistical analysis was performed on these results. Ryan et al. (45) detected a significant decrease in insulin $(-6.7 \pm 5.3$ $\mathrm{mIU} / \mathrm{L}, p<0.01)$ in the Mediterranean diet compared to the low-fat diet.

Meta-analyses for glucose parameters could be only performed for the Mediterranean diet due to lack of studies on the hypocaloric diet. The meta-analysis in Figure 4A shows non-significant changes in fasting glucose concentration (SMD: $0.14,95 \%$ CI: $-0.18,0.45)$ after the Mediterranean diet compared to the low-fat diet. Heterogeneity was not detected $\left(I^{2}=0 \%\right.$, $\tau^{2}=0, p=0.51$ ).

Meta-analysis for fasting insulin in the Mediterranean diet showed no change (SMD: $-0.10,95 \%$ CI: $-0.15,0.96)$ (Figure 4B). Heterogeneity was significant and high $\left(I^{2}=89 \%\right.$, $\left.\tau^{2}=0.7598, p<0.01\right)$.

The homeostatic model assessment for insulin resistance was not significantly reduced in the Mediterranean diet (SMD: -0.50 , 95\% CI: $-1.93,0.93$ ) (Figure 4C). The heterogeneity was high $\left(I^{2}=86 \%, \tau^{2}=0.9189, p<0.01\right)$.

\section{Lipid Parameters}

In the hypocaloric dietary interventions, Shidfar et al. (41) did not measure any lipid parameters and Jang et al. (39) did not measure HDL-C concentration. Razavi et al. (40) reported a decrease in TG concentration $(-31.3 \pm 38.8 \mathrm{mg} / \mathrm{dL}, p=0.006)$ only in the DASH group. Arefhosseini et al. (38) reported a significant decrease of TG concentration in the control group $(-39.8 \pm 56.5$ $\mathrm{mg} / \mathrm{dl}, p=0.023$ ). Jang et al. (39) detected a significant reduction 
A

\begin{tabular}{|c|c|c|c|c|c|c|c|c|c|c|c|c|}
\hline \multirow[b]{2}{*}{ Study } & \multirow[b]{2}{*}{ Total } & \multicolumn{2}{|c|}{ Experimental } & & Control & \multicolumn{2}{|c|}{ Standardised Mean } & \multirow{2}{*}{\multicolumn{2}{|c|}{ SMD }} & \multirow{2}{*}{\multicolumn{2}{|c|}{$\begin{array}{ll} & \text { Weight } \\
95 \%-\mathrm{Cl} & \text { (fixed) }\end{array}$}} & \multirow{2}{*}{$\begin{array}{r}\text { Weight } \\
\text { (random) }\end{array}$} \\
\hline & & Mean & SD & Total & Mean SD & Dif & erence & & & & & \\
\hline Razavi et al., 2016 & 30 & -8.40 & 12.7201 & 30 & 3.808 .1409 & $\because$ & & & -1.13 & {$[-1.68 ;-0.58]$} & $52.7 \%$ & $52.7 \%$ \\
\hline Shidfar et al., 2018 & 25 & -12.29 & 7.8056 & 28 & -4.646 .5246 & & & & -1.05 & {$[-1.63 ;-0.48]$} & $47.3 \%$ & $47.3 \%$ \\
\hline \multirow{3}{*}{$\begin{array}{l}\text { Fixed effect model } \\
\text { Random effects model } \\
\text { Heterogeneity: } I^{2}=0 \%, \tau^{2}=\end{array}$} & 55 & & & 58 & & 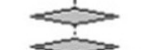 & & & -1.09 & {$[-1.49 ;-0.69]$} & $100.0 \%$ & \\
\hline & $=0.0=$ & & & & & $\infty_{1}$ & & & -1.09 & {$[-1.49 ;-0.69]$} & -- & $100.0 \%$ \\
\hline & & & & & & $\begin{array}{lll}-1.5 & -1 & -0.5\end{array}$ & 0.51 & 1.5 & & & & \\
\hline
\end{tabular}

B

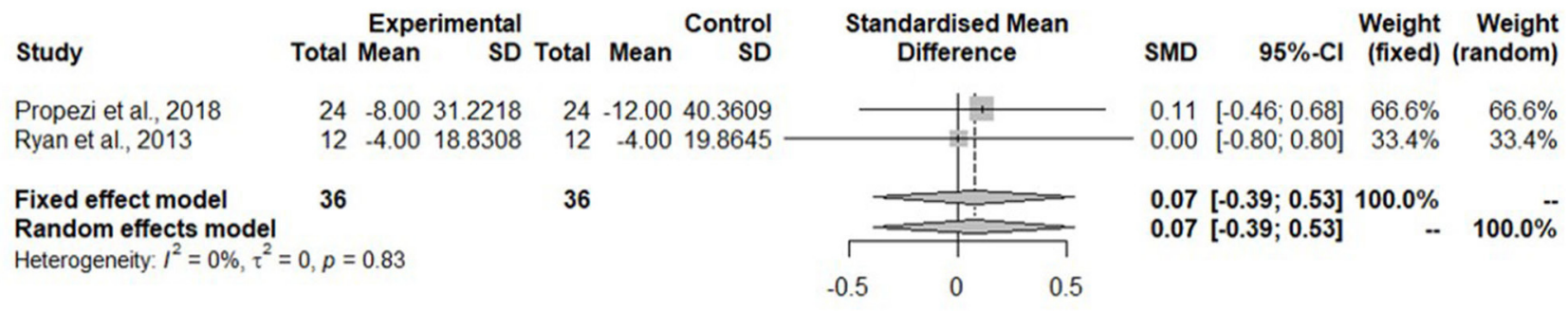

C

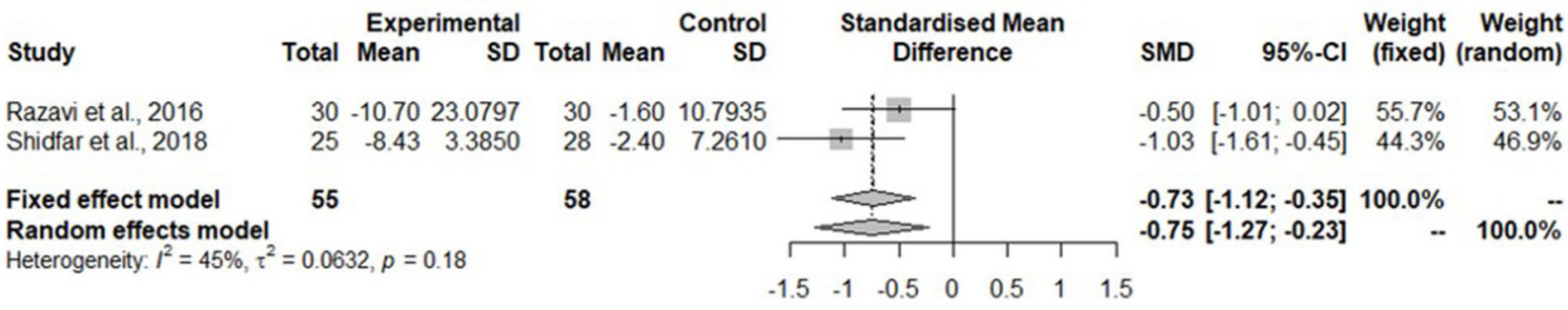

D

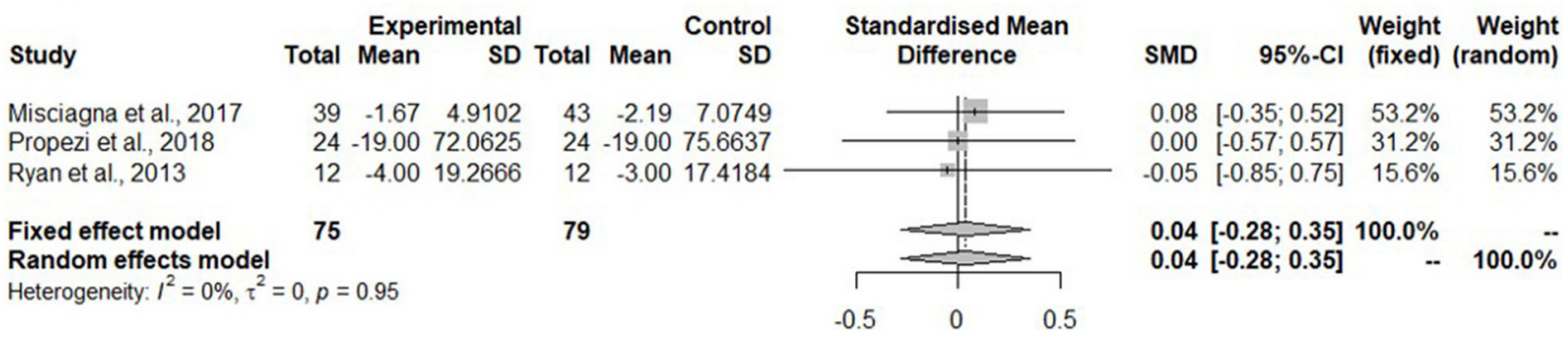

FIGURE 3 | Forest plots of (A) alanine aminotransferase (ALT) in hypo-caloric group; (B) ALT in isocaloric group; (C) aspartate aminotransferase (AST) in hypocaloric group; (D) gamma-glutamyl transferase ( $\gamma \mathrm{GT})$ in isocaloric group; SD, standard deviation; SMD, standardized mean difference.

of LDL-C concentration in low carbohydrate intervention arm $(-7.1 \pm 16.5 \mathrm{mg} / \mathrm{dl}, p<0.001)$ compared to the control group. For isocaloricdietary interventions, Ryan et al. (45) did not measure the concentrations of TC and LDL-C. The tendency of the studies with the Mediterranean diet is similar. Compared to its low-fat control group, TC concentration did not change in the Mediterranean diet groups. Dorosti et al. (42) showed significant differences in the concentrations of LDL-C $(-12.9$ $\pm 12.0 \mathrm{mg} / \mathrm{dL}, p<0.05)$ and HDL-C $(1.8 \pm 4.2 \mathrm{mg} / \mathrm{dL}$, $p<0.05)$ in the whole-grain diet compared to the group with usual cereals, but after adjusting, no significant changes were observed. Propezi et al. (44) reported significant reductions in TC $(-9.6 \pm 31.4 \mathrm{mg} / \mathrm{dL}, p=0.01)$ and TG $(-21.4 \pm$ $48.2 \mathrm{mg} / \mathrm{dL}, p=0.008)$ concentrations in the Mediterranean diet. Misciagna et al. (43) performed no statistical tests on lipid parameters.

Meta-analyses for all lipid parameters were only performed in the isocaloric group (Mediterranean group) due to lack of 
A

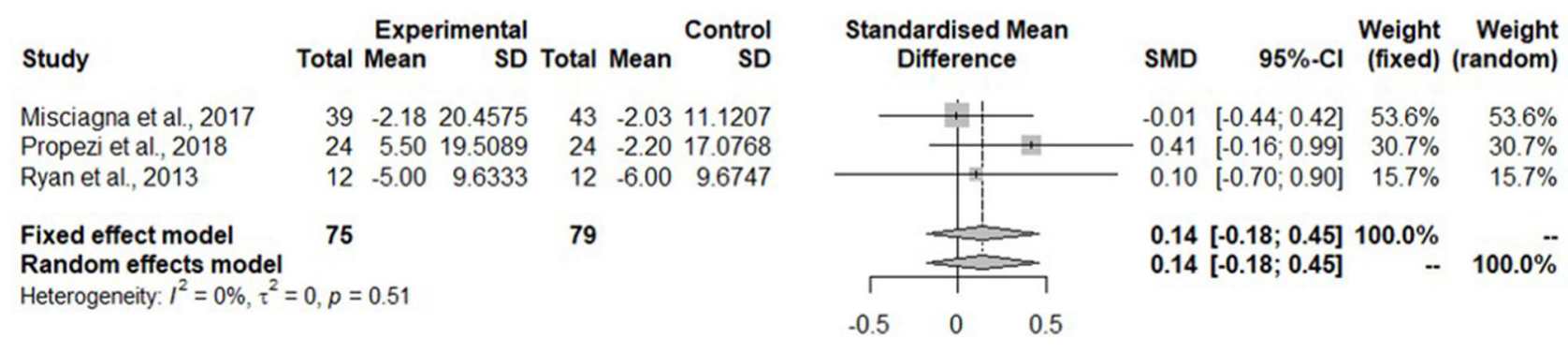

B

\section{Study}

Misciagna et al., 2017

Propezi et al., 2018

Ryan et al., 2013

Fixed effect model

Random effects model

Heterogeneity: $I^{2}=89 \%, \tau^{2}=0.7598, p<0.01$

75
Experimental Total Mean SD Total Mean SD

$\begin{array}{lll}39 & -2.91 & 12.4209\end{array}$

$\begin{array}{lll}24 & 3.13 & 5.2916\end{array}$

$\begin{array}{lll}12 & -6.70 & 5.3413\end{array}$

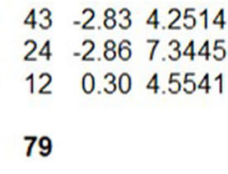

$\begin{array}{rrr}43 & -2.83 & 4.2514 \\ 24 & -2.86 & 7.3445 \\ 12 & 0.30 & 4.5541 \\ & & \\ 79 & & \end{array}$
Standardised Mean Difference

\begin{tabular}{|c|c|c|}
\hline $95 \%-\mathrm{Cl}$ & $\begin{array}{l}\text { Weight } \\
\text { (fixed) }\end{array}$ & $\begin{array}{r}\text { Weight } \\
\text { (random) }\end{array}$ \\
\hline$-0.01 \quad[-0.44 ; 0.43]$ & $57.0 \%$ & $36.0 \%$ \\
\hline $0.92[0.32 ; 1.52]$ & $30.0 \%$ & $34.1 \%$ \\
\hline$-1.36[-2.27 ;-0.46]$ & $13.1 \%$ & $29.9 \%$ \\
\hline $\begin{array}{r}0.09[-0.23 ; 0.42] \\
-0.10[-1.15 ; 0.96]\end{array}$ & $\begin{array}{r}100.0 \% \\
\ldots\end{array}$ & $100.0 \%$ \\
\hline
\end{tabular}

C

Study

Experimental

Control Total Mean SD Total Mean SD

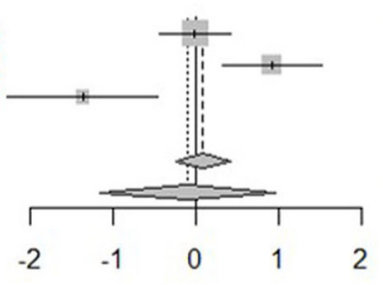

Standardised Mean Difference

$\begin{array}{lll}24 & 0.19 & 3.2352\end{array}$

$\begin{array}{llll}12 & -1.70 & 0.9675\end{array}$

36

$\begin{array}{lll}24 & -0.28 & 1.2175\end{array}$

$\begin{array}{llll}12 & -0.20 & 1.2907\end{array}$

36

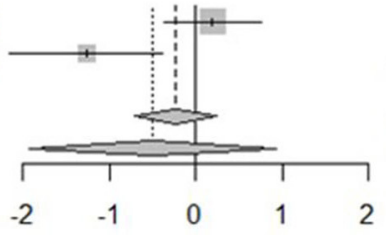

WMDight Weight $95 \%-\mathrm{Cl}$ (fixed) (random)

$0.19[-0.38 ; 0.76] \quad 71.2 \% \quad 52.9 \%$

$-1.27[-2.16 ;-0.38] \quad 28.8 \% \quad 47.1 \%$

$\begin{array}{lrr}-0.23[-0.71 ; 0.25] & 100.0 \% & - \\ -0.50[-1.93 ; 0.93] & -- & 100.0 \%\end{array}$

Rixed effect model

Heterogeneity: $I^{2}=86 \%, \tau^{2}=0.9189, p<0.01$

\section{.}

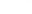

FIGURE 4 | Forest plots of (A) fasting glucose in isocaloric diet; (B) fasting insulin in isocaloric diet; (C) homeostatic model assessment for insulin resistance (HOMA-IR) in isocaloric diet; SD, standard deviation; SMD, standardized mean difference.

studies in the hypocaloric group (Figure 5). The TC was not significantly reduced in the Mediterranean diet compared to the control group (SMD: $-0.11,95 \% \mathrm{CI}:-0.46,0.23)$ and no heterogeneity was detected $\left(I^{2}=0 \%, \tau^{2}=0, p=0.62\right)$ (Figure 5A).

Figure 5B shows no changes in the LDL-C concentration in the Mediterranean diet (SMD:-0.05, 95\% CI:-0.41, 0.30). No heterogeneity was detected $\left(I^{2}=0 \%, \tau^{2}=0, p=0.81\right)$. Misciagna et al. (43) had different total subject numbers for this analysis because LDL-C concentration was not measured in all of the subjects.

High-density lipoprotein cholesterol concentration (Figure 5C) showed no changes (SMD: 0.03, 95\% CI: $-0.29,0.35)$. There was no heterogeneity $\left(I^{2}=0 \%, \tau^{2}=\right.$ $0, p=0.51)$. The TG concentration did not change in the Mediterranean diet (SMD: $-0.28,95 \%$ CI: $-0.60,0.03$ ). There was no heterogeneity $\left(I^{2}=0 \%, \tau^{2}=0, p=0.99\right)$ (Figure 4D).

\section{DISCUSSION}

In this systematic review, the effect of dietary interventions without any exercise or physical activity on NAFLD and related clinical parameters (IHL, ALT, AST, $\gamma$ GT, fasting glucose, fasting insulin, HOMA-IR TC, LDL-C, HDL-C, and TG) were reviewed and analyzed. In total, eight studies fulfilled the inclusion criteria. Dietary interventions were grouped based on the energy intake in the studies resulting in four studies in each group. Further assessment was applied based on the composition of the dietary interventions in order to perform the meta-analysis. This led to the selection of two (hypocaloric dietary interventions) or three (isocaloric dietary interventions) studies for pooled comparisons. Our meta-analysis shows that the Mediterranean diet reduces liver fat in patients with NAFLD, and a hypocaloric dietary approach favoring unsaturated fatty acids reduces liver transaminases as a clinical proxy for NASH; yet no conclusions can be drawn on active or fibrotic NASH. 


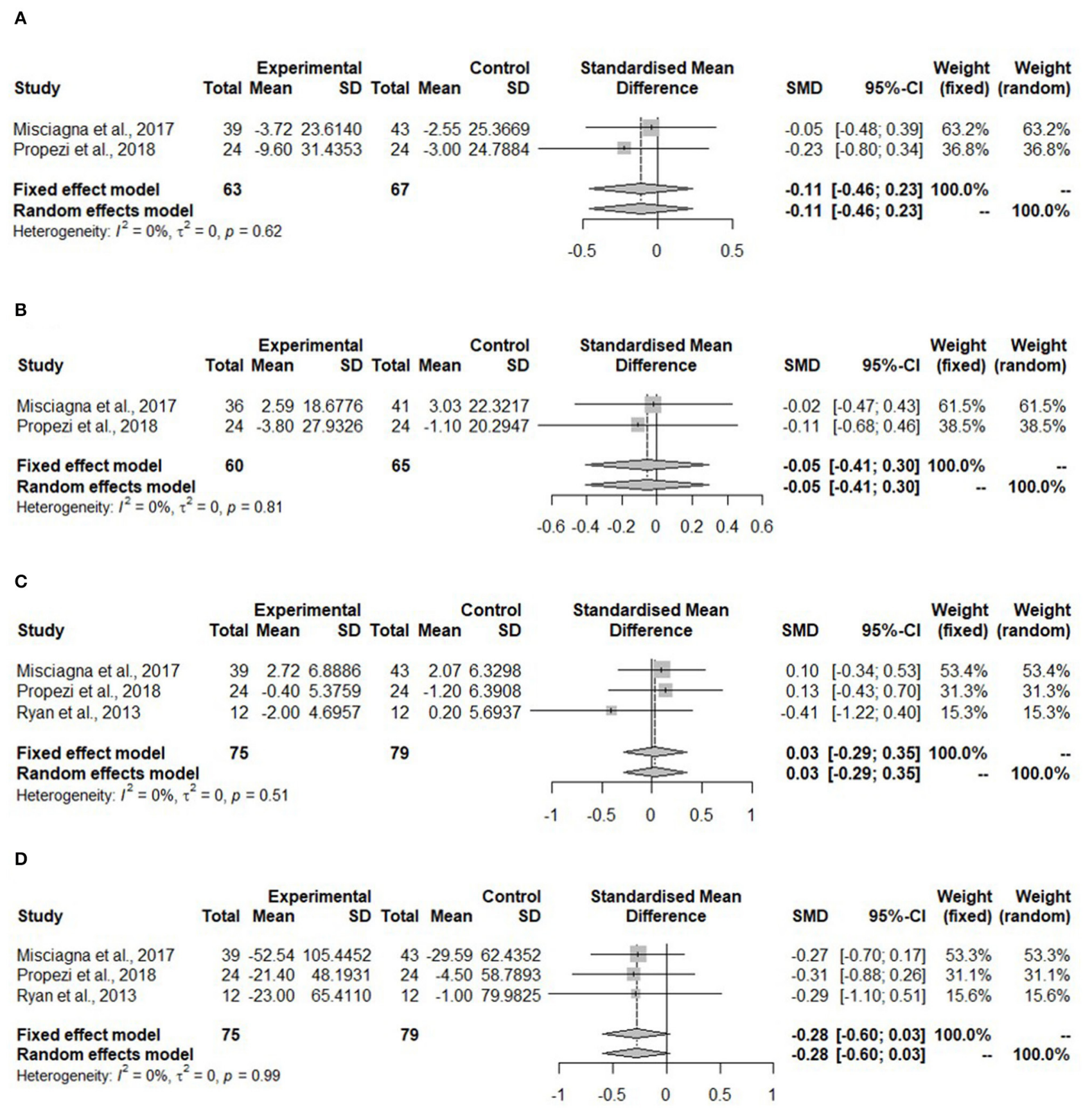

FIGURE 5 | Forest plots of (A) total cholesterol (TC) in isocaloric diet; (B) low-density lipoprotein cholesterol (LDL-C) in isocaloric diet; (C) high-density lipoprotein cholesterol (HDL-C) in isocaloric diet; (D) triglycerides (TG) in isocaloric diet; SD, standard deviation; SMD, standardized mean difference.

We were able to replicate the findings from previous systematic reviews investigating the Mediterranean diet on the liver fat $(31,47)$. The Mediterranean diet without caloric restriction reduced the liver fat compared to the control group in patients with NAFLD. Propezi et al. (44) and Ryan et al. (45) constructed the Mediterranean diet based on the actual reported data on the consumption of a Cretan diet with similar composition of macronutrients from similar sources, whereas the study by Misciagna et al. (43) did not report any basis on the construction of the diet. However, it contained similar macronutrient composition and foods, and they also used a Mediterranean adequacy index (MAI) to follow the adherence to the diet. Based on the information on the diet compositions, the diets in these studies can be considered comparable. In general, the Mediterranean diet is characterized by high proportion of unsaturated fatty acids, including polyunsaturated 
fatty acids (PUFA) and monounsaturated fatty acids (MUFA) whose main sources are vegetable oils, fish, nuts, and seeds. These can contribute to the beneficial effects on the liver fat (48). For instance, higher consumption of walnuts has been shown to associate with a greater improvement of the liver fat in patients with NAFLD (49). In general, the Mediterranean diet is associated with a $56 \%$ decreased risk for NAFLD in a cross-sectional setting (48). Moreover, the Mediterranean diet is also composed of vegetables, fruits, legumes, and whole-grain products that are high in dietary fiber. In fact, the intake of dietary fiber is inversely associated with NAFLD (50). Additionally, the study by Dorosti et al. (42), which was not a part of the meta-analysis, showed a resolution in steatosis, together with a decrease in the liver enzymes after a 12-week whole-grain diet compared to the control diet with usual cereal consumption. This effect may be explained partly due to the fiber content and its effects on the digestion and the gut microbiome, and also due to the properties of phenolic compounds from the wholegrain foods. These phenolic compounds include anthocyanins and flavonoids that have been associated with anti-inflammatory properties and the so called antioxidants $(51,52)$. However, a supplementation of antioxidants did not give any additional benefits to the Mediterranean diet on the liver fat, but together with green tea, the liver fat improved more significantly than with the diet alone (53). Furthermore, the gut microbiome might mediate some of the metabolic effects of the Mediterranean diet which could contribute to the regression of $\operatorname{NAFLD}(49,50,54)$. The change in IHL after an 18-month Mediterranean diet was independently associated with the gut microbial compositional changes, depicted in $\beta$-diversity and taxa level (49). In general, the diet has distinct impacts on the gut microbiome, and certain gut microbial signatures has been related to NAFLD (55-58). Therefore, investigating this triangle could give more insights on the mechanisms behind the effects of dietary interventions on NAFLD.

Interestingly, the study by Jang et al. (39), one of the hypocaloric dietary interventions, detected a significant decrease in IHL in a low-carbohydrate diet compared to a low-fat diet. However, their low-carbohydrate diet had $50-60 \%$ of energy intake as carbohydrates being still in a normal range of carbohydrate intake, and $20-25 \%$ of fat which was higher than in the low-fat diet (15-20\%). A SR reported that replacing total fats with total carbohydrates does not reduce the liver fat; however, types of carbohydrates were not able to be assessed due to lack of reporting. In turn, replacing saturated fats with unsaturated fats is beneficial to the liver fat (32). Proportion of nutrients toward higher unsaturated fat ratio could contribute to steatosis regression. All individual hypocaloric dietary interventions reported a decrease of IHL together with a significant weight loss but due to the different methods for measuring IHL, an overall effect via meta-analysis could not be assessed. Altogether, the dietary fiber and unsaturated fatty acids from foods in the Mediterranean diet can be considered one of the dietary components contributing to the beneficial effects of the Mediterranean diet on the liver fat.

The pooled effect of two hypocaloric diets containing foods high in unsaturated fatty acids show reduction on liver transaminases, such as ALT and AST, compared to the control group $(40,41)$. We were not able to do meta-analysis on the liver fat with these studies due to the different assessment techniques, but all hypocaloric studies reported a significant decrease in IHL (38-41). Our results of the liver transaminases are in accordance with the previous studies, where a hypocaloric diet improved the liver function through weight loss supporting the beneficial effect of hypocaloric diet via weight loss on the liver-related parameters (59, 60). A dose-response relationship between weight loss and improvements in the liver-related outcomes in patients with NAFLD has been reported previously; a hypocaloric diet targeting to $5-7 \%$ weight loss reduced steatosis, while over $10 \%$ weight loss significantly improved NASH and fibrosis (25, 61). Furthermore, the meta-analysis of the Mediterranean diet showed a tendency toward increased ALT levels. Additionally, the levels of $\gamma \mathrm{GT}$ did not show any significant change after the Mediterranean dietary interventions compared to the control diet. Similar results have been reported also by other SR before (40). It is known that $\gamma \mathrm{GT}$ is dependent on age, gender, and alcohol consumption (62). However, in all the three studies, high alcohol consumption was an exclusion criterion and it was not changed during the interventions. A non-significant change could be explained by several other factors, such as medication, smoking, and several other diseases, which are all associated with increased $\gamma \mathrm{GT}$ (63-65). None of the Mediterranean dietary intervention studies reported significant change in weight between intervention or control group, but studies by Propezi et al. (44) and Misciagna et al. (43) showed significant weight loss within the groups. Regarding the macronutrient composition of dietary interventions, the effect of macronutrient composition on the liver enzymes is still controversial (32). The study by Arefhosseini et al. (38) aimed to address this with two hypocaloric diets with different macronutrient compositions, where both diets were as effective on hepatic outcomes (the liver enzymes and echogenicity) indicating weight loss-induced effects, despite macronutrient composition. In turn, Jang et al. (39) reported greater and significant improvement of ALT in the low-carbohydrate group compared to the low-fat group. Limited number of studies limits our conclusions with respect to the liver enzymes. Overall, hypocaloric dietary interventions in this systematic review showed a significant improvement in the liver enzymes, but our meta-analysis supports dietary interventions with foods high in unsaturated fatty acids.

Our systematic review does not show significant changes in the concentrations of fasting glucose or insulin or HOMAIR in studies with the Mediterranean diet. Similar results have been reported in other studies, where the Mediterranean diet does not show significant improvements in fasting glucose or insulin concentrations over the control diet, but HOMA-IR, as a surrogate marker for the insulin resistance, showed a significant improvement in another SRs in patients with NAFLD $(31,47)$. This could be due to the limited number of studies in our SR. However, an improvement of HOMA-IR could indicate a decline in the insulin resistance. Insulin resistance is thought to be the major driver for NAFLD, but it mainly concerns patients without a genetic predisposition, the genetic variant of the gene that encodes patatin-like phospholipase 
domain-containing protein 3 (PNPLA3) $(66,67)$. Unfortunately, we were not able to investigate the influence of the genetic variants in our meta-analysis due to lack of data and reported endpoints in the studies. However, individual assessment of the isocaloric studies indicates a significant improvement of HOMA-IR only in one study with the Mediterranean diet (45) and no effect in two studies with either the Mediterranean or a whole-grain diet $(42,44)$. No significant changes in glucose or insulin concentrations compared to the control diet were reported in either of the isocaloric studies (4245). None of the hypocaloric dietary interventions showed significant changes in insulin and glucose concentrations $(39,40)$ or HOMA-IR (40). Ultimately, dietary intervention studies, both hypo and isocaloric, investigating parameters related to glucose metabolism in patients with NAFLD are controversial. More studies are needed in order to assess different dietary approaches to glucose metabolism in patients with NAFLD.

Our meta-analysis shows no significant reduction but a strong trend toward improvement in TG concentrations in isocaloric studies. This trend is in line with other SRs investigating the effect of the Mediterranean diet on cardiovascular risk factors in NAFLD $(6,68)$. Elevated TGs and their increased ratio to HDL-C are associated with the increased risk of CVD and its outcomes $(69,70)$, as well as LDL-C concentration is strongly linked to coronary heart disease (71). Moreover, the Mediterranean diet has been linked to reduced risk for cardiometabolic diseases which are thought to be explained by the beneficial effects of vegetable oils, nuts, and seeds which are low in saturated fatty acids and high in unsaturated fatty acids and fiber. It may be also partly due to the effects of phytosterols and phytostanols affecting the intestinal cholesterol absorption (72-74). However, in our pooled analysis with the Mediterranean diet, TC or lipoprotein cholesterol concentrations (HDL-C, LDL-C) did not show significant changes. This is also in line with other SRs that do not report changes in lipoprotein cholesterol concentrations in the Mediterranean diet in patients with NAFLD (47). Moreover, individual assessment of all studies in our review showed that isocaloric dietary interventions can improve plasma lipid profile in patients with NAFLD. The hypocaloric DASH diet with increased intake of foods high in unsaturated fatty acids reported a decrease in concentrations of triglycerides, TC, and LDL-C (40), but unfortunately, pooled effect on lipids could not be investigated with any of the hypocaloric interventions. A clinically significant decrease in TG concentration in the intervention group was shown by Razavi et al. (40). Arefhosseini et al. (38) showed that only a hypocaloric diet with decreased intake of both carbohydrates and dietary fat decreased the concentration of TGs significantly compared to the other diet. Also, Jang et al. (39) reported an increase with a low-carbohydrate diet. Cross-sectional data show that the intake of cholesterol and consumption of foods high in saturated fatty acids have been associated with the risk for NAFLD (50). In general, limiting the intake of unsaturated fatty acids is associated with the lower risk of cardiovascular events (75). As CVD is the main cause of mortality among patients with NAFLD, the quality of dietary fats and other sources of fat, such as meat and dairy, require special attention (76). Additionally, the Western type of dietary pattern high in processed foods, refined grains, and saturated fatty acids from high fat dairy and meat increase the risk for NAFLD by $23 \%$ (48).

Currently, dietary modification, exercise, or the combination of both, targeting weight loss is the key therapy for NAFLD (21-24). Our results showed that the Mediterranean diet without weight loss can also improve the liver parameters. Both dietary interventions in this SR are in accordance with EASL, ESPEN, AGA, and AASLD guidelines, where a hypocaloric or the Mediterranean diet is suggested as a dietary treatment for NAFLD. However, current guidelines do not address the optimal dietary strategy specifically for active, fibrotic, and cirrhotic NASH, although it contributes to the overall burden of the disease, not only on the $t$ point of view of patients but also economically on the public health (7780). Due to this burden, different stages, especially active and fibrotic NASH, cannot be disregarded when designing future studies. Furthermore, based on the knowledge of the distinct metabolic effects of genetic variants on the pathophysiology on NAFLD, the genetic predispositions should have more attention in lifestyle interventions. We suggest that more RCTs with different comparable dietary intervention studies including well-characterized NAFLD patients and valid endpoint measures, including histology and/or multiparametric imaging are warranted in order to identify and address the optimal dietary approaches in the future guidelines. This would help clinicians to develop care pathways and target their resources efficiently in the different stages of NAFLD. However, compliance and successful treatment require that the patient is motivated and engaged to the lifestyle modifications $(81,82)$. Therefore, the optimal treatment of NAFLD should be patient-centered and multidisciplinary (83). In order to achieve these goals, we need more awareness from the policy, care pathway, and guideline creators $(83,84)$. Additionally, NAFLD should be incorporated in the national health prevention and care strategies due to its large public health burden.

One of the main strengths of this SR is the study inclusion criteria, which resulted in a well-characterized study population focusing on NAFLD. Also, studies were limited to dietary interventions without any kind of exercise or physical activity intervention. To the best of our knowledge, this has not been done before in SRs investigating dietary interventions in patients with NAFLD. Moreover, the quality assessment was conducted by a tool which is specifically designed for dietary intervention studies in a three-category grading system. This allows more detailed and valid assessment of the quality of the studies. However, this paper has also some limitations. First, due to the small number of studies, meta-analyses were limited. In addition, most of the studies were performed in Iran which could cause some bias. Therefore, the reliability of the results should be interpreted with some caution. With a higher number of studies, it would be probably possible to show more robust effects of different dietary interventions in several parameters. Consequently, a publication-bias detection analysis could not be performed due to the lack of power with a small number of studies. Another limitation is the missing genetic predispositions. 
Genetic variants should be assessed in dietary intervention studies since the presence of those variants affect lipid and glucose metabolism. Moreover, most of the studies do not report the severity and the activity of the disease which potentially affects the endpoints. Thus, by reporting this and its influence on the results could improve the analysis.

In conclusion, the Mediterranean and hypocaloric dietary interventions favoring unsaturated fatty acids result in improvements in IHL independent of weight loss, and transaminases are reduced in the hypocaloric diets with weight loss in patients with NAFLD. Since many dietary intervention studies are combined with exercise interventions or physical activity, the diet effect alone is not investigated enough. In addition, to the best of our knowledge, studies addressing the genetic background in diet interventions are missing. Furthermore, more advanced and clinically relevant stages of NAFLD, that is active and fibrotic NASH, with multiparametric imaging and liver histology as outcome measures, are not sufficiently considered. Therefore, the optimal dietary invention in NAFLD remains to be defined.

\section{DATA AVAILABILITY STATEMENT}

Publicly available datasets were analyzed in this study. This data can be found at: The data is retrieved from the listed articles in the manuscript.

\section{REFERENCES}

1. Younossi ZM, Koenig AB, Abdelatif D, Fazel Y, Henry L, Wymer M. Global epidemiology of nonalcoholic fatty liver disease-Meta-analytic assessment of prevalence, incidence, and outcomes. Hepatology. (2016) 64:7384. doi: 10.1002/hep.28431

2. Younossi Z, Tacke F, Arrese M, Chander Sharma B, Mostafa I, Bugianesi E, et al. Global perspectives on nonalcoholic fatty liver disease and nonalcoholic steatohepatitis. Hepatology. (2019) 69:2672-82. doi: 10.1002/hep.30251

3. Kim D, Kim WR. Nonobese fatty liver disease. Clin Gastroenterol Hepatol. (2017) 15:474-85. doi: 10.1016/j.cgh.2016.08.028

4. Puri P, Sanyal AJ. Nonalcoholic fatty liver disease: definitions, risk factors, and workup. Clin liver Dis. (2012) 1:99-103. doi: 10.1002/cld.81

5. Lonardo A, Ballestri S, Guaraldi G, Nascimbeni F, Romagnoli D, Zona S, et al. Fatty liver is associated with an increased risk of diabetes and cardiovascular disease - Evidence from three different disease models: NAFLD, HCV and HIV. World J Gastroenterol. (2016) 22:9674-93. doi: 10.3748/wjg.v22.i44. 9674

6. Cobbina E, Akhlaghi F. Non-alcoholic fatty liver disease (NAFLD) - pathogenesis, classification, and effect on drug metabolizing enzymes and transporters. Drug Metab Rev. (2017) 49:197-211. doi: 10.1080/03602532.2017.1293683

7. Cotter TG, Rinella M. Nonalcoholic fatty liver disease 2020: the state of the disease. Gastroenterology. (2020) 158:185164. doi: 10.1053/j.gastro.2020.01.052

8. Dulai PS, Singh S, Patel J, Soni M, Prokop LJ, Younossi Z, et al. Increased risk of mortality by fibrosis stage in nonalcoholic fatty liver disease: systematic review and meta-analysis. Hepatology. (2017) 65:155765. doi: 10.1002/hep.29085

9. Taylor RS, Taylor RJ, Bayliss S, Hagström H, Nasr P, Schattenberg JM, et al. Association between fibrosis stage and outcomes of patients with nonalcoholic fatty liver disease: a systematic review and meta-analysis. Gastroenterology. (2020) 158:1611-25.e12. doi: 10.1053/j.gastro.2020.01.043

\section{AUTHOR CONTRIBUTIONS}

SC and VH contributed equally to the organization as well as in writing, reviewing, and editing of the manuscript. Data extraction and quality assessment were also performed by SC and $\mathrm{VH}$ with the assistance of US. SC performed the statistical analyses for the meta-analysis. $\mathrm{MN}, \mathrm{AH}$, and US reviewed, edited, and supervised the manuscript. All authors contributed to the article and approved the submitted version.

\section{FUNDING}

This work has received funding from the European Union's Horizon 2020 research and innovation program under the Marie Skłodowska-Curie grant agreement No. 813781 ITN BestTreat (on which SC and $\mathrm{VH}$ are appointed). AH was supported by the Amsterdam UMC Fellowship grant, Health-Holland TKIPPP grants, and by the research grants from Gilead and Novo Nordisk. MN was supported by a personal ZONMW VICI grant 2020 [09150182010020].

\section{ACKNOWLEDGMENTS}

We thank Heikki Laitinen from the University of Eastern Finland, Kuopio for his great help with the search-term combinations.

10. Assy N, Kaita K, Mymin D, Levy C, Rosser B, Minuk G. Fatty infiltration of liver in hyperlipidemic patients. Dig Dis Sci. (2000) 45:192934. doi: 10.1023/a:1005661516165

11. Leite NC, Salles GF, Araujo ALE, Villela-Nogueira CA, Cardoso CRL. Prevalence and associated factors of non-alcoholic fatty liver disease in patients with type-2 diabetes mellitus. Liver Int. (2009) 29:1139. doi: 10.1111/j.1478-3231.2008.01718.x

12. Younossi ZM, Golabi P, de Avila L, Paik JM, Srishord M, Fukui N, et al. The global epidemiology of NAFLD and NASH in patients with type 2 diabetes: A systematic review and meta-analysis. J Hepatol. (2019) 71:793801. doi: 10.1016/j.jhep.2019.06.021

13. Zoppini G, Fedeli U, Gennaro N, Saugo M, Targher G, Bonora E. Mortality from chronic liver diseases in diabetes. Am J Gastroenterol. (2014) 109:10205. doi: 10.1038/ajg.2014.132

14. Kumar R, Priyadarshi RN, Anand U. Non-alcoholic fatty liver disease: growing burden, adverse outcomes and associations. J Clin Transl Hepatol. (2020) 8:76-86. doi: 10.14218/JCTH.2019.00051

15. Malhotra P, Gill RK, Saksena S, Alrefai WA. Disturbances in cholesterol homeostasis and non-alcoholic fatty liver diseases. Front Med. (2020) 7:467. doi: 10.3389/fmed.2020.00467

16. Zelber-Sagi S, Nitzan-Kaluski D, Goldsmith R, Webb M, Blendis L, Halpern $\mathrm{Z}$, et al. Long term nutritional intake and the risk for non-alcoholic fatty liver disease (NAFLD): a population based study. J Hepatol. (2007) 47:7117. doi: 10.1016/j.jhep.2007.06.020

17. Yki-Järvinen $H$. Nutritional modulation of non-alcoholic fatty liver disease and insulin resistance. Nutrients. (2015) 7:9127-38. doi: 10.3390/nu7115454

18. Umbro I, Fabiani V, Fabiani M, Angelico F, Del Ben M. Association between non-alcoholic fatty liver disease and obstructive sleep apnea. World J Gastroenterol. (2020) 26:2669-81. doi: 10.3748/wjg.v26.i20.2669

19. Aron-Wisnewsky J, Vigliotti C, Witjes J, Le P, Holleboom AG, Verheij J, et al. Gut microbiota and human NAFLD: disentangling microbial signatures from metabolic disorders. Nat Rev Gastroenterol Hepatol. (2020) 17:27997. doi: 10.1038/s41575-020-0269-9 
20. Prussick R, Prussick L, Nussbaum D. Nonalcoholic Fatty liver disease and psoriasis: what a dermatologist needs to know. J Clin Aesthet Dermatol. (2015) 8:43-5.

21. Chalasani N, Younossi Z, Lavine JE, Diehl AM, Brunt EM, Cusi K, et al. The diagnosis and management of non-alcoholic fatty liver disease: practice Guideline by the American Association for the Study of Liver Diseases, American College of Gastroenterology, and the American Gastroenterological Association. Hepatology. (2012) 55:2005-23. doi: 10.1002/hep.25762

22. European Association for the Study of the Liver (EASL), European Association for the Study of Diabetes (EASD), European Association for the Study of Obesity (EASO). EASL-EASD-EASO Clinical Practice Guidelines for the Management of Non-Alcoholic Fatty Liver Disease. Obes Facts. (2016) 9:65-90. doi: 10.1159/000443344

23. Bischoff SC, Bernal W, Dasarathy S, Merli M, Plank LD, Schütz T, et al. ESPEN practical guideline: clinical nutrition in liver disease. Clin Nutr. (2020) 39:3533-62. doi: 10.1016/j.clnu.2020.09.001

24. Younossi ZM, Corey KE, Lim JK. AGA clinical practice update on lifestyle modification using diet and exercise to achieve weight loss in the management of nonalcoholic fatty liver disease: expert review. Gastroenterology. (2021) 160:912-8. doi: 10.1053/j.gastro.2020.11.051

25. Vilar-Gomez E, Martinez-Perez Y, Calzadilla-Bertot L, Torres-Gonzalez A, Gra-Oramas B, Gonzalez-Fabian L, et al. Weight loss through lifestyle modification significantly reduces features of nonalcoholic steatohepatitis. Gastroenterology. (2015) 149:367-78.e5. doi: 10.1053/j.gastro.2015.04.005

26. Hohenester S, Christiansen S, Nagel J, Wimmer R, Artmann R, Denk G, et al. Lifestyle intervention for morbid obesity: effects on liver steatosis, inflammation, and fibrosis. Am J Physiol Gastrointest Liver Physiol. (2018) 315:G329-38. doi: 10.1152/ajpgi.00044.2018

27. Jegatheesan P, De Bandt J-P. Fructose and NAFLD: the multifaceted aspects of fructose metabolism. Nutrients. (2017) 9:230. doi: 10.3390/nu9030230

28. Zelber-Sagi S, Ratziu V, Oren R. Nutrition and physical activity in NAFLD: an overview of the epidemiological evidence. World J Gastroenterol. (2011) 17:3377-89. doi: 10.3748/wjg.v17.i29.3377

29. Working group set up by the Finnish Medical Society Duodecim and The Finnish Association for General Practice. Non-Alcoholic Fatty Liver Disease (NAFLD). Current Care Guidelines. Helsinki Finnish Med Soc Duodecim. (2020). Available online at: www.kaypahoito.fi (accessed June 9, 2021).

30. Parnell JA, Raman M, Rioux KP, Reimer RA. The potential role of prebiotic fibre for treatment and management of non-alcoholic fatty liver disease and associated obesity and insulin resistance. Liver Int. (2012) 32:70111. doi: 10.1111/j.1478-3231.2011.02730.x

31. Moosavian SP, Arab A, Paknahad Z. The effect of a Mediterranean diet on metabolic parameters in patients with non-alcoholic fatty liver disease: A systematic review of randomized controlled trials. Clin Nutr ESPEN. (2020) 35:40-6. doi: 10.1016/j.clnesp.2019.10.008

32. Winters-van Eekelen E, Verkouter I, Peters HPF, Alssema M, de Roos BG, Schrauwen-Hinderling VB, et al. Effects of dietary macronutrients on liver fat content in adults: a systematic review and meta-analysis of randomized controlled trials. Eur J Clin Nutr. (2021) 75:588-601. doi: 10.1038/s41430-020-00778-1

33. Moher D, Liberati A, Tetzlaff J, Altman DG. Preferred reporting items for systematic reviews and meta-analyses: the PRISMA statement. BMJ. (2009) 339:b2535. doi: 10.1136/bmj.b2535

34. Page MJ, McKenzie JE, Bossuyt PM, Boutron I, Hoffmann TC, Mulrow CD, et al. The PRISMA 2020 statement: an updated guideline for reporting systematic reviews. BMJ. (2021) 372:n71. doi: 10.1136/bmj.n71

35. Ouzzani M, Hammady H, Fedorowicz Z, Elmagarmid A. Rayyana web and mobile app for systematic reviews. Syst Rev. (2016) 5:210. doi: 10.1186/s13643-016-0384-4

36. Chung M, Balk EM, Brendel M, Ip S, Lau J, Lee J, et al. Vitamin D and calcium: a systematic review of health outcomes. Evid Rep Technol Assess. (2009) 183:1-420.

37. Higgins JPT, Thomas J, Chandler J, Cumpston M, Li T, Page MJ WV. No Title. Cochrane Handb Syst Rev Interv version (2021).

38. Arefhosseini SR, Ebrahimi-Mameghani M, Farsad Naeimi A, Khoshbaten M, Rashid J. Lifestyle modification through dietary intervention: health promotion of patients with non-alcoholic fatty liver disease. Heal Promot Perspect. (2011) 1:147-54. doi: 10.5681/hpp.2011.016
39. Jang EC, Jun DW, Lee SM, Cho YK, Ahn SB. Comparison of efficacy of low-carbohydrate and low-fat diet education programs in non-alcoholic fatty liver disease: A randomized controlled study. Hepatol Res. (2018) 48:E229. doi: 10.1111/hepr.12918

40. Razavi Zade M, Telkabadi MH, Bahmani F, Salehi B, Farshbaf S, Asemi Z. The effects of DASH diet on weight loss and metabolic status in adults with non-alcoholic fatty liver disease: a randomized clinical trial. Liver Int. (2016) 36:563-71. doi: 10.1111/liv.12990

41. Shidfar F, Bahrololumi SS, Doaei S, Mohammadzadeh A, Gholamalizadeh M, Mohammadimanesh A. The effects of extra virgin olive oil on alanine aminotransferase, aspartate aminotransferase, and ultrasonographic indices of hepatic steatosis in nonalcoholic fatty liver disease patients undergoing low calorie diet. Can J Gastroenterol Hepatol. (2018) 2018:1053710. doi: 10.1155/2018/1053710

42. Dorosti M, Jafary Heidarloo A, Bakhshimoghaddam F, Alizadeh M. Wholegrain consumption and its effects on hepatic steatosis and liver enzymes in patients with non-alcoholic fatty liver disease: a randomised controlled clinical trial. Br J Nutr. (2020) 123:328-36. doi: 10.1017/S0007114519002769

43. Misciagna G, Del Pilar Díaz M, Caramia D V, Bonfiglio C, Franco I, Noviello $\mathrm{MR}$, et al. Effect of a low glycemic index mediterranean diet on non-alcoholic fatty liver disease. A randomized controlled clinici trial. J Nutr Health Aging. (2017) 21:404-12. doi: 10.1007/s12603-016-0809-8

44. Properzi C, O'Sullivan TA, Sherriff JL, Ching HL, Jeffrey GP, Buckley RF, et al. Ad libitum mediterranean and low-fat diets both significantly reduce hepatic steatosis: a randomized controlled trial. Hepatology. (2018) 68:174154. doi: 10.1002/hep. 30076

45. Ryan MC, Itsiopoulos C, Thodis T, Ward G, Trost N, Hofferberth S, et al The mediterranean diet improves hepatic steatosis and insulin sensitivity in individuals with non-alcoholic fatty liver disease. J Hepatol. (2013) 59:13843. doi: 10.1016/j.jhep.2013.02.012

46. Appel LJ, Moore TJ, Obarzanek E, Vollmer WM, Svetkey LP, Sacks FM, et al. A clinical trial of the effects of dietary patterns on blood pressure. DASH Collaborative Research Group. N Engl J Med. (1997) 336:111724. doi: 10.1056/NEJM199704173361601

47. Akhlaghi M, Ghasemi-Nasab M, Riasatian M. Mediterranean diet for patients with non-alcoholic fatty liver disease, a systematic review and meta-analysis of observational and clinical investigations. J Diabetes Metab Disord. (2020) 19:575-84. doi: 10.1007/s40200-019-00475-2

48. Hassani Zadeh S, Mansoori A, Hosseinzadeh M. Relationship between dietary patterns and non-alcoholic fatty liver disease: A systematic review and metaanalysis. J Gastroenterol Hepatol. (2020) 36:1470-8. doi: 10.1111/jgh.15363

49. Yaskolka Meir A, Rinott E, Tsaban G, Zelicha H, Kaplan A, Rosen P, et al. Effect of green-Mediterranean diet on intrahepatic fat: the DIRECT PLUS randomised controlled trial. Gut. (2021). doi: 10.1136/gutjnl-2020-323106

50. Noureddin M, Zelber-Sagi S, Wilkens LR, Porcel J, Boushey CJ, Le Marchand $\mathrm{L}$, et al. Diet associations with nonalcoholic fatty liver disease in an ethnically diverse population: the multiethnic cohort. Hepatology. (2020) 71:194052. doi: 10.1002/hep.30967

51. Toma L, Sanda G, Niculescu L, Deleanu M, Sima A, Stancu C. Phenolic compounds exerting lipid-regulatory, anti-inflammatory and epigenetic effects as complementary treatments in cardiovascular diseases. Biomolecules. (2020) 10:641. doi: 10.3390/biom10040641

52. Lutz M, Fuentes E, Ávila F, Alarcón M, Palomo I. Roles of phenolic compounds in the reduction of risk factors of cardiovascular diseases. Molecules. (2019) 24:366. doi: 10.3390/molecules24020366

53. Abenavoli L, Greco M, Milic N, Accattato F, Foti D, Gulletta E, et al. Effect of mediterranean diet and antioxidant formulation in non-alcoholic fatty liver disease: a randomized study. Nutrients. (2017) 9:870. doi: 10.3390/nu90 80870

54. Wang DD, Nguyen LH, Li Y, Yan Y, Ma W, Rinott E, et al. The gut microbiome modulates the protective association between a Mediterranean diet and cardiometabolic disease risk. Nat Med. (2021) 27:333-43. doi: 10.1038/s41591-020-01223-3

55. Yuan J, Chen C, Cui J, Lu J, Yan C, Wei X, et al. Fatty liver disease caused by high-alcohol-producing klebsiella pneumoniae. Cell Metab. (2019) 30:67588.e7. doi: 10.1016/j.cmet.2019.08.018

56. Zhu L, Baker SS, Gill C, Liu W, Alkhouri R, Baker RD, et al. Characterization of gut microbiomes in nonalcoholic steatohepatitis (NASH) patients: a 
connection between endogenous alcohol and NASH. Hepatology. (2013) 57:601-9. doi: 10.1002/hep.26093

57. Schwimmer JB, Johnson JS, Angeles JE, Behling C, Belt PH, Borecki I, et al. Microbiome signatures associated with steatohepatitis and moderate to severe fibrosis in children with nonalcoholic fatty liver disease. Gastroenterology. (2019) 157:1109-22. doi: 10.1053/j.gastro.2019.06.028

58. Johnson AJ, Vangay P, Al-Ghalith GA, Hillmann BM, Ward TL, Shields-Cutler RR, et al. Daily sampling reveals personalized dietmicrobiome associations in humans. Cell Host Microbe. (2019) 25:789-802.e5. doi: 10.1016/j.chom.2019.05.005

59. Promrat K, Kleiner DE, Niemeier HM, Jackvony E, Kearns M, Wands JR, et al. Randomized controlled trial testing the effects of weight loss on nonalcoholic steatohepatitis. Hepatology. (2010) 51:121-9. doi: 10.1002/hep.23276

60. Musso G, Cassader M, Rosina F, Gambino R. Impact of current treatments on liver disease, glucose metabolism and cardiovascular risk in non-alcoholic fatty liver disease (NAFLD): a systematic review and meta-analysis of randomised trials. Diabetologia. (2012) 55:885-904. doi: 10.1007/s00125-011-2446-4

61. Wong VW-S, Chan RS-M, Wong GL-H, Cheung BH-K, Chu WC-W, Yeung DK-W, et al. Community-based lifestyle modification programme for nonalcoholic fatty liver disease: a randomized controlled trial. J Hepatol. (2013) 59:536-42. doi: 10.1016/j.jhep.2013.04.013

62. Tynjälä J, Kangastupa P, Laatikainen T, Aalto M, Niemelä O. Effect of age and gender on the relationship between alcohol consumption and serum GGT: time to recalibrate goals for normal ranges. Alcohol Alcohol. (2012) 47:558-62. doi: 10.1093/alcalc/ags072

63. Isojärvi JI, Pakarinen AJ, Myllylä VV. Basic haematological parameters, serum gamma-glutamyl-transferase activity, and erythrocyte folate and serum vitamin B12 levels during carbamazepine and oxcarbazepine therapy. Seizure. (1997) 6:207-11. doi: 10.1016/s1059-1311(97)80007-6

64. Whitehead TP, Robinson D, Allaway SL. The effects of cigarette smoking and alcohol consumption on serum liver enzyme activities: a dose-related study in men. Ann Clin Biochem. (1996) 33:530-5. doi: 10.1177/000456329603300607

65. Koenig G, Seneff S. Gamma-glutamyltransferase: a predictive biomarker of cellular antioxidant inadequacy and disease risk. Dis Markers. (2015) 2015:818570. doi: 10.1155/2015/818570

66. Isokuortti E, Zhou Y, Peltonen M, Bugianesi E, Clement K, BonnefontRousselot D, et al. Use of HOMA-IR to diagnose non-alcoholic fatty liver disease: a population-based and inter-laboratory study. Diabetologia. (2017) 60:1873-82. doi: 10.1007/s00125-017-4340-1

67. Yki-Järvinen H. Non-alcoholic fatty liver disease as a cause and a consequence of metabolic syndrome. Lancet Diabetes Endocrinol. (2014) 2:901-10. doi: 10.1016/S2213-8587(14)70032-4

68. Asbaghi O, Choghakhori R, Ashtary-Larky D, Abbasnezhad A. Effects of the Mediterranean diet on cardiovascular risk factors in non-alcoholic fatty liver disease patients: A systematic review and meta-analysis. Clin Nutr ESPEN. (2020) 37:148-56. doi: 10.1016/j.clnesp.2020.03.003

69. Salazar MR, Carbajal HA, Espeche WG, Aizpurúa M, Leiva Sisnieguez CE, March CE, et al. Identifying cardiovascular disease risk and outcome: use of the plasma triglyceride/high-density lipoprotein cholesterol concentration ratio versus metabolic syndrome criteria. J Intern Med. (2013) 273:595601. doi: 10.1111/joim.12036

70. Chen Z, Chen G, Qin H, Cai Z, Huang J, Chen H, et al. Higher triglyceride to high-density lipoprotein cholesterol ratio increases cardiovascular risk: 10year prospective study in a cohort of Chinese adults. J Diabetes Investig. (2020) 11:475-81. doi: 10.1111/jdi.13118

71. Ueda P, Gulayin P, Danaei G. Long-term moderately elevated LDL-cholesterol and blood pressure and risk of coronary heart disease. PLOS ONE. (2018) 13:e0200017. doi: 10.1371/journal.pone.0200017
72. Devaraj S, Jialal I. The role of dietary supplementation with plant sterols and stanols in the prevention of cardiovascular disease. Nutr Rev. (2006) 64:348-54. doi: 10.1111/j.1753-4887.2006.tb00219.x

73. De Smet E, Mensink RP, Konings M, Brufau G, Groen AK, Havinga R, et al. Acute intake of plant stanol esters induces changes in lipid and lipoprotein metabolism-related gene expression in the liver and intestines of mice. Lipids. (2015) 50:529-41. doi: 10.1007/s11745-015-4020-1

74. Sanclemente T, Marques-Lopes I, Puzo J, García-Otín AL. Role of naturallyoccurring plant sterols on intestinal cholesterol absorption and plasmatic levels. J Physiol Biochem. (2009) 65:87-98. doi: 10.1007/BF03165972

75. Hooper L, Martin N, Jimoh OF, Kirk C, Foster E, Abdelhamid AS. Reduction in saturated fat intake for cardiovascular disease. Cochrane Database Syst Rev. (2020) 8:CD011737. doi: 10.1002/14651858.CD011737.pub3

76. Targher G, Corey KE, Byrne CD. NAFLD, and cardiovascular and cardiac diseases: Factors influencing risk, prediction and treatment. Diabetes Metab. (2021) 47:101215. doi: 10.1016/j.diabet.2020.101215

77. CGordon S, Fraysse J, Li S, Ozbay AB, Wong RJ. Disease severity is associated with higher healthcare utilization in nonalcoholic steatohepatitis medicare patients. Am J Gastroenterol. (2020) 115:562-74. doi: 10.14309/ajg.0000000000000484

78. Romero-Gomez M, Kachru N, Zamorano MA, Darba J, Shreay S. Disease severity predicts higher healthcare costs among hospitalized nonalcoholic fatty liver disease/nonalcoholic steatohepatitis (NAFLD/NASH) patients in Spain. Medicine. (2020) 99:e23506. doi: 10.1097/MD.0000000000023506

79. O'Hara J, Finnegan A, Dhillon H, Ruiz-Casas L, Pedra G, Franks B, et al. Cost of non-alcoholic steatohepatitis in Europe and the USA: The GAIN study. JHEP Rep Innov Hepatol. (2020) 2:100142. doi: 10.1016/j.jhepr.2020.100142

80. McSweeney L, Breckons M, Fattakhova G, Oluboyede Y, Vale L, Ternent L, et al. Health-related quality of life and patient-reported outcome measures in NASH-related cirrhosis. JHEP Rep Innov Hepatol. (2020) 2:100099. doi: 10.1016/j.jhepr.2020.100099

81. Toft UN, Kristoffersen LH, Aadahl M, von Huth Smith L, Pisinger C, Jørgensen T. Diet and exercise intervention in a general population-mediators of participation and adherence: the Inter99 study. Eur J Public Health. (2007) 17:455-63. doi: 10.1093/eurpub/ckl262

82. Sebire SJ, Toumpakari Z, Turner KM, Cooper AR, Page AS, Malpass A, et al. "I've made this my lifestyle now": a prospective qualitative study of motivation for lifestyle change among people with newly diagnosed type two diabetes mellitus. BMC Public Health. (2018) 18:204. doi: 10.1186/s12889-018-5114-5

83. Lazarus J V, Palayew A, Carrieri P, Ekstedt M, Marchesini G, Novak $\mathrm{K}$, et al. European "NAFLD Preparedness Index" - Is Europe ready to meet the challenge of fatty liver disease? JHEP Rep Innov Hepatol. (2021) 3:100234. doi: 10.1016/j.jhepr.2021.100234

84. Lazarus J V, Ekstedt M, Marchesini G, Mullen J, Novak K, Pericàs JM, et al. A cross-sectional study of the public health response to non-alcoholic fatty liver disease in Europe. J Hepatol. (2020) 72:14-24. doi: 10.1016/j.jhep.2019. 08.027

Conflict of Interest: The authors declare that the research was conducted in the absence of any commercial or financial relationships that could be construed as a potential conflict of interest.

Copyright (c) 2021 Houttu, Csader, Nieuwdorp, Holleboom and Schwab. This is an open-access article distributed under the terms of the Creative Commons Attribution License (CC BY). The use, distribution or reproduction in other forums is permitted, provided the original author(s) and the copyright owner(s) are credited and that the original publication in this journal is cited, in accordance with accepted academic practice. No use, distribution or reproduction is permitted which does not comply with these terms. 